\title{
Parameterisation, validation and implementation of an all-terrain SUV FTire tyre model
}

Hans-Rudolf B. Bosch, Herman A. Hamersma \& P. Schalk Els*

Department of Mechanical and Aeronautical Engineering

\author{
University of Pretoria
}

South Africa

\begin{abstract}
*Corresponding author.
E-mail address: schalk.els@up.ac.za

Telephone: +27124202045

E-mail address:

hansrudolfbosch@gmail.com (H. B. Bosch)

hermanh@up.ac.za (H.A. Hamersma)

schalk.els@up.ac.za (P. S. Els)
\end{abstract}

\section{Highlights}

- Static and dynamic tyre parameterization tests.

- Parameterization of an FTire model.

- Validation on smooth road surfaces.

- Validation on rough terrain.

- Implementation on full vehicle model on rough terrain. 


\begin{abstract}
This paper focuses the parameterisation, validation and implementation of an FTire model of a Michelin LTX A/T $235 / 85 \mathrm{R} 16$ tyre. This tyre is designed for both on- and off-road use and is commonly used on all wheel drive SUVs. Quasi-static laboratory and dynamic field tests were conducted to acquire parameterisation and validation test data for the FTire model. Quasi-static parameterisation tests include acquiring vertical tyre stiffness over a flat plate and cleats, tyre footprint sizes and shapes, longitudinal, lateral and torsional tyre stiffness for various tyre normal loads, as well as vibrational tyre responses. Dynamic parameterisation tests include dynamic cleat test data. An Adams model of the tyre testing equipment is implemented to simulate the FTire model and validate it against dynamic validation test results. Finally, the model is implemented on a fully nonlinear multi-body dynamics model of a Land Rover Defender.
\end{abstract}

It is found that the FTire model is able to predict the lateral tyre behaviour well on a smooth road surface. The vertical and longitudinal tyre behaviour on a smooth road surface and on a rough surface are predicted accurately.

Keywords: FTire, static tyre tests, dynamic tyre tests, tyre model parameterisation, tyre model validation, tyre model implementation

\title{
1 Introduction
}

When considering a moving vehicle, the only external forces acting on it are the forces generated in the contact patch and the aerodynamic forces (Gillespie, 1992). Therefore, the accurate simulation of the tyre-road interaction is of utmost importance to ensure accurate simulation results. For many years research has been directed towards characterising the forces between the tyre contact patch and the road surface.

To simulate the ride and handling characteristics of a vehicle, the forces experienced by the vehicle must be modelled accurately. It is essential that each of the subsystems are modelled accurately to ensure reliable simulation results. Hence the forces acting on the vehicle should be modelled as 
accurately as possible. Many tyre models have been developed over several decades. One of the most widely used models is the Pacejka Magic Formula curve fit, formulated in the 1980s (Bakker et al., 1989). Most of these earlier methods were empirically based and did not take the tyre physics into account explicitly. These empirical models made use of point-follower contact methods and are known for their simplicity and high computational efficiency in the simulation environment (Bakker et al., 1989). Stallmann et al. (2014) found that point-contact methods are not sufficient for modelling tyres over short wavelength irregularities encountered in off-road terrain profiles or discrete obstacles. The need for a physics-based tyre model, which can be implemented to predict the ride and handling characteristics of a tyre over both on and off-road terrains, has arisen.

The FTire tyre model, developed by Cosin (2014), is a physics based model in which the tyre is modelled as a three dimensional nonlinear structural dynamics type model that can be used for vehicle dynamics simulations on even and uneven road surfaces. The model consists of bending, tangential, lateral and radial stiffnesses and damping. The tyre is numerically approximated with a predetermined number of elements. FTire claims to be capable of accurately predicting the forces and moments generated by the tyre on smooth as well as uneven road surfaces for on-road tyres, which agrees with the findings of Stallmann et al. (2014), although their study focussed on much larger tyres. The tyre belt is represented by a flexible ring that can be displaced and bent in arbitrary directions. The ring is numerically approximated with a finite number of belt elements that are coupled with their direct neighbours with bending stiffness (Gipser, 2005). FTire is designed for use in multi-body dynamics simulation models such as ride comfort and handling simulations as well as road load prediction models for durability applications on road irregularities with very short wavelengths. The main disadvantage of using FTire is the large number of parameters required to parameterise the tyre model and an increased computational cost.

The tyre of interest is a Michelin LTX A/T $235 / 85 \mathrm{R} 16$. This tyre is often found on sports-utilityvehicles (SUVs) and presents a unique challenge to tyre modelling, because of its wide range of implementation on paved roads and on off-road road trails and tracks. The tyre is thus used in conditions ranging from highway speeds to very low speed off-road manoeuvres. 


\subsection{Parameterising FTire}

The required parameterisation data consists of static and dynamic tests. To construct an FTire model, Cosin's FTire/fit (Cosin, 2014) is used to process the data obtained in static and dynamic parameterisation tests. The following parameterisation tests were conducted:

1. Tyre cross section outer contour in $\mathrm{x} / \mathrm{y}$ data pairs

2. Tyre footprint at half load index (LI) load and full LI load at two camber angles (one may be zero)

3. Shore A hardness

4. Vertical tyre stiffness on a flat surface

5. Vertical tyre stiffness on a transverse cleat

6. Vertical tyre stiffness on an oblique $\left(45^{\circ}\right.$ angle) cleat

7. Vertical tyre stiffness on a longitudinal cleat

8. Vertical tyre stiffness on a flat surface at a five degree camber angle

9. Vertical tyre stiffness on a transversal cleat at a five degree camber angle

10. Lateral tyre stiffness on a flat surface

11. Longitudinal tyre stiffness on a flat surface

12. Torsional tyre stiffness on a flat surface

13. Tyre modal analysis

14. Dynamic cleat test data to determine vertical tyre damping

The quasi-static flat surface and cleat test data give extensive information about the tread and sidewall stiffnesses of the tyre. Quasi-static in-plane and out-of-plane tyre stiffness test data captures the lateral, longitudinal and torsional stiffnesses of the tyre and serves to parameterise the handling and traction parameters of the FTire model. Tyre modal analysis test results are required by FTire/fit (Cosin, 2014) to parameterise the dynamic response and damping parameters of the FTire model. Furthermore, dynamic cleat test data is required to parameterise the damping characteristics of the FTire model.

\subsection{Model validation and implementation}

After the tyre model has been parameterised, validation of the model is essential. Validation of the tyre model is performed by comparing field measured longitudinal force, lateral force and vertical response data to simulated data. An outdoor tyre test trailer is used to obtain handling and traction validation data over a smooth road surface and vertical validation data over uneven road surfaces and discrete obstacles. The handling validation test data deals with the lateral force vs. slip angle characteristics of the tyre while the longitudinal force validation data deals with the brake force 
characteristics of the tyre over smooth road surfaces. The vertical validation data deals with the vertical tyre response while the tyre is travelling over discrete obstacles and uneven road surfaces such as cleats and an undulating road surface, specifically a Belgian paving. The FTire model is then simulated in MSC Adams (MSC Software Corporation, 2013) and validated against the measured dynamic validation field test data.

Finally the developed tyre model is implemented on a fully non-linear multi-body dynamics model of a Land Rover Defender. Brake tests are performed with the Land Rover Defender on a Belgian Paving. During the brake tests the vehicle is instrumented with a Wheel Force Transducer (Becker \& Els, 2012). These tests are repeated in MSC Adams and the measured wheel forces are compared with the simulated wheel forces.

\section{Tyre model parameterisation}

The ability of a tyre model to predict tyre behaviour relies heavily on the underlying formulation of the model and whether this is detailed enough to predict the required behaviour. The ability of the FTire model to predict tyre behaviour relies on the accuracy of the parameterisation data as well as the optimisation of the parameters.

\subsection{Quasi-static parameterisation tests}

Laboratory tests were performed on the non-rolling tyre to determine the footprint size and shape, vertical stiffness on a flat plate as well as over $25 \times 25 \mathrm{~mm}$ and $32 \times 32 \mathrm{~mm}$ cleats. The tests were repeated at different camber angles, tyre pressures and vertical loads. Furthermore, the in-plane and out-of-plane tyre stiffnesses of the tyre are measured and a modal analysis is performed on the tyre.

The experimental setups and procedures used in the parameterisation tests are described in the following Sections. Integral to capturing the forces and moments exerted on the tyre is a Wheel Force Transducer (WFT), described by Becker and Els (2012). The WFT measures the forces and moments generated by the tyre about all three Cartesian axes. 


\subsubsection{Tyre footprint and vertical tyre stiffness on a flat surface}

The experimental setup to determine the tyre footprint size and shape consists of a horizontally mounted hydraulic actuator which pushes a toughened glass plate against the tyre, also orientated horizontally, as shown in Figure 1. The tyre is tested for 0, 100 and $200 \mathrm{kPa}$ gauge pressures as well as $0^{\circ}, 3^{\circ}$ and $5^{\circ}$ camber angles. A low frequency sinusoidal normal load is applied to the tyre.

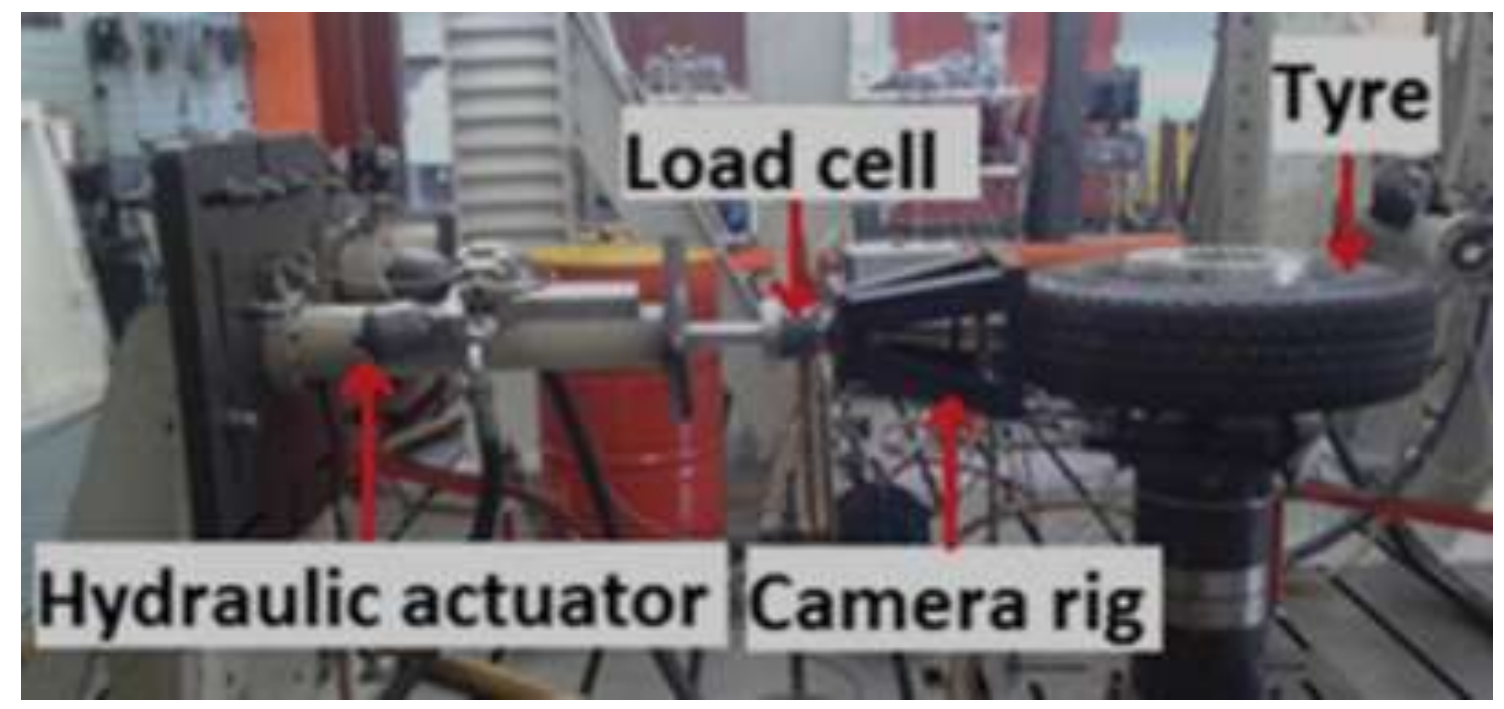

Figure 1: Glass plate experimental setup

The hydraulic actuator displacement is measured by a Linear Variable Differential Transformer (LVDT) fitted to the actuator, while the load exerted by the actuator is measured by the wheel force transducer (WFT) (Becker \& Els, 2012) and a load cell. The measured displacements and forces are used to determine the vertical force-displacement characteristics of the tyre during the testing procedure, as depicted in Figure 2. 


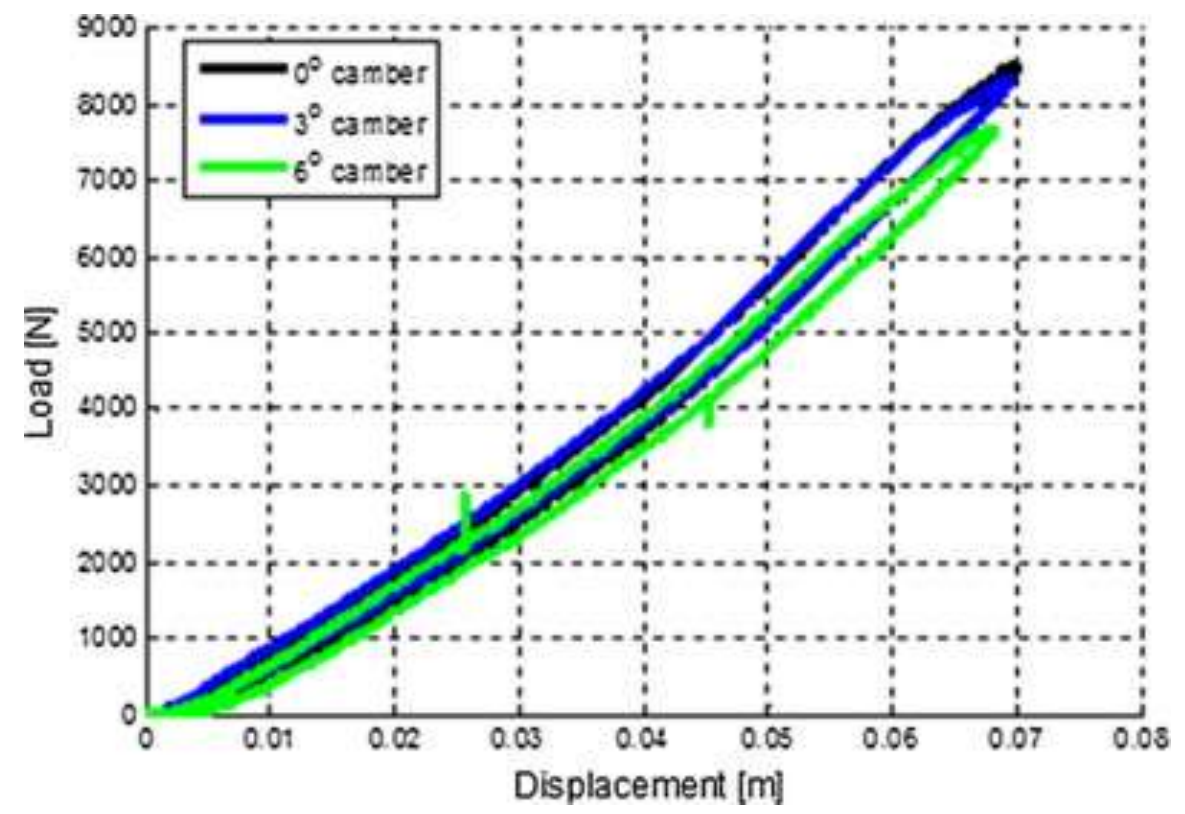

Figure 2: Vertical tyre stiffness for different camber angles at $200 \mathrm{kPa}$ inflation pressure

A bullet proof glass plate is utilized in the experimental procedure to capture images of the tyre footprints while the tests are executed. Stereo-vision imaging was implemented to capture the size and shape of the footprint. Shown in Figure 3 is the footprint as captured with the stereo-vision cameras. The black areas shown is the part of the tyre in contact with the glass plate - the white sections are areas where there is no rubber in contact with the glass. This is due to the tread pattern of the tyre.

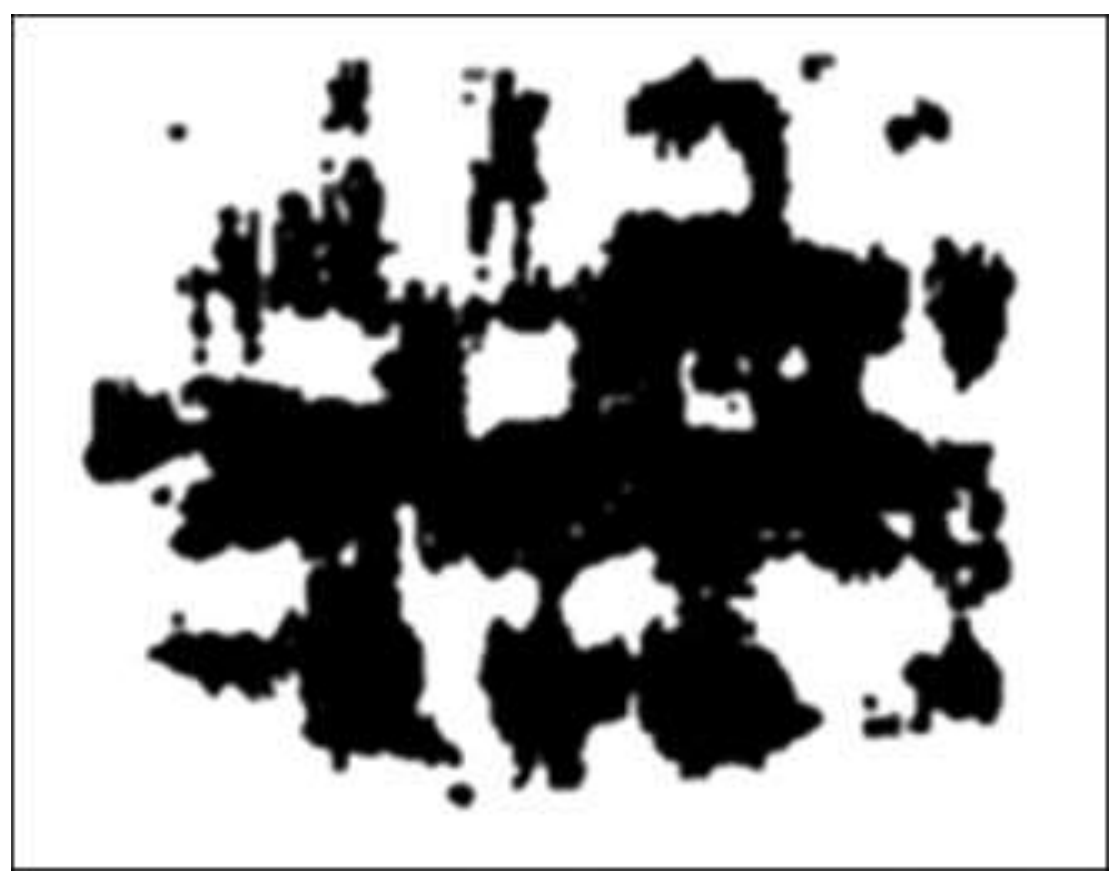

Figure 3: Footprint image at a vertical load of $1790 \mathrm{~N}$ and an inflation pressure of 2 bar 


\subsubsection{Vertical tyre stiffness over cleats}

Static cleat tests were performed on the tyre in a similar experimental setup as with the vertical stiffness tests, but the flat glass plate is replaced with a steel plate. Square cleats $(25 \times 25 \mathrm{~mm}$ and $32 \times 32 \mathrm{~mm}$ in cross section) are bolted to the steel plate mounted to the hydraulic actuator. The static cleat tests were repeated for three configurations with the cleats orientated transversal, longitudinal and oblique ( $45^{\circ}$ direction) relative to the heading of the tyre. The tyre was tested with the same inflation pressures, camber angles and vertical loads as with the flat plate tests of Section 2.1.1. Test results are shown in Figure 4.

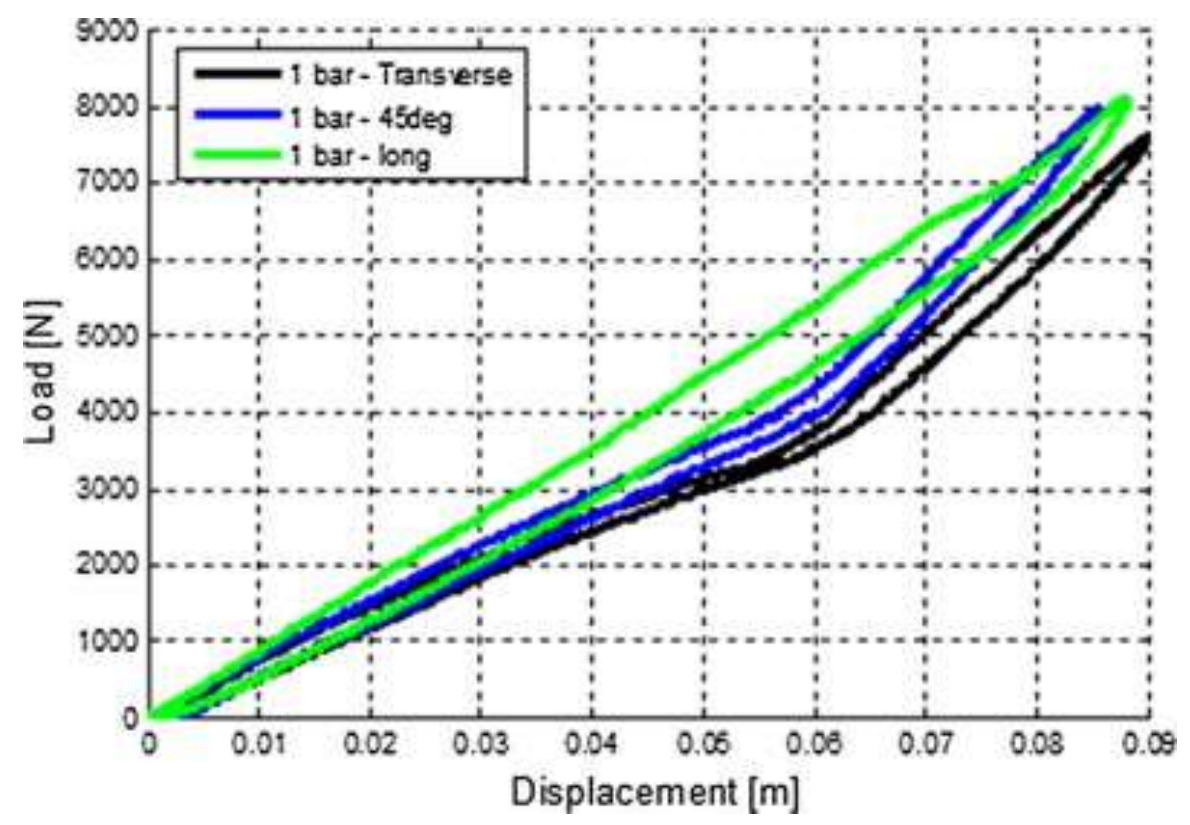

Figure 4: Experimental results of three different cleat orientations $(25 \times 25 \mathrm{~mm}$ cleat $)$ at $1 \mathrm{bar}$ inflation pressure and $0^{\circ}$ camber angle

\subsubsection{In-plane and out-of-plane tyre friction}

To determine the lateral, longitudinal and torsional tyre stiffnesses a steel plate was mounted to the hydraulic actuator with linear guide rails as indicated in Figure 5. The tyre is preloaded with a normal force with a hydraulic actuator and the plate on the guide rails is then smoothly pulled from between the tyre and the hydraulic actuator. The plate's displacement was measured and a corresponding plot of force as a function of the measured displacement was determined. By pulling the plate in the 
longitudinal and lateral directions relative to the tyre, the in-plane and out-of-plane tyre stiffnesses and friction coefficients were determined.

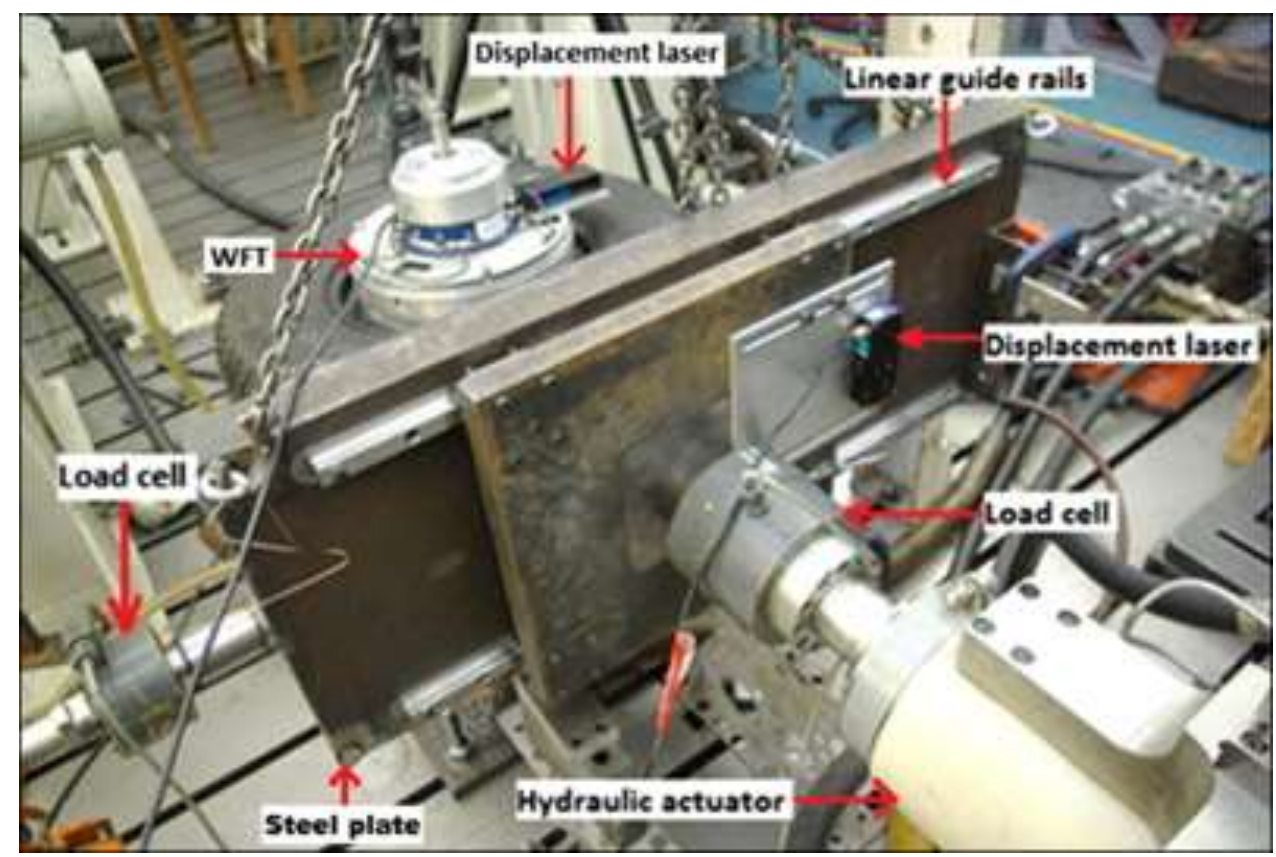

Figure 5: Longitudinal in-plane friction experimental setup

Results for the static longitudinal tyre stiffness tests are indicated in Figure 6. From Figure 6 it may be seen that while maintaining a constant vertical load on the tyre the longitudinal force increases linearly as the tyre is displaced longitudinally over the steel plate. Once the friction coefficient is exceeded the tyre starts to slide longitudinally and the longitudinal force remains constant after sliding occurs. Similar results were found while translating the steel plate laterally. The in-plane friction coefficient (longitudinal) was found to be 0.85 while the out-of-plane (lateral) coefficient of friction was found to be 0.90 . To determine the out-of-plane torsional stiffness of the tyre the steel plate was rotated about its centre while the linear rails were secured to ensure no translation during the torsional testing procedure. 


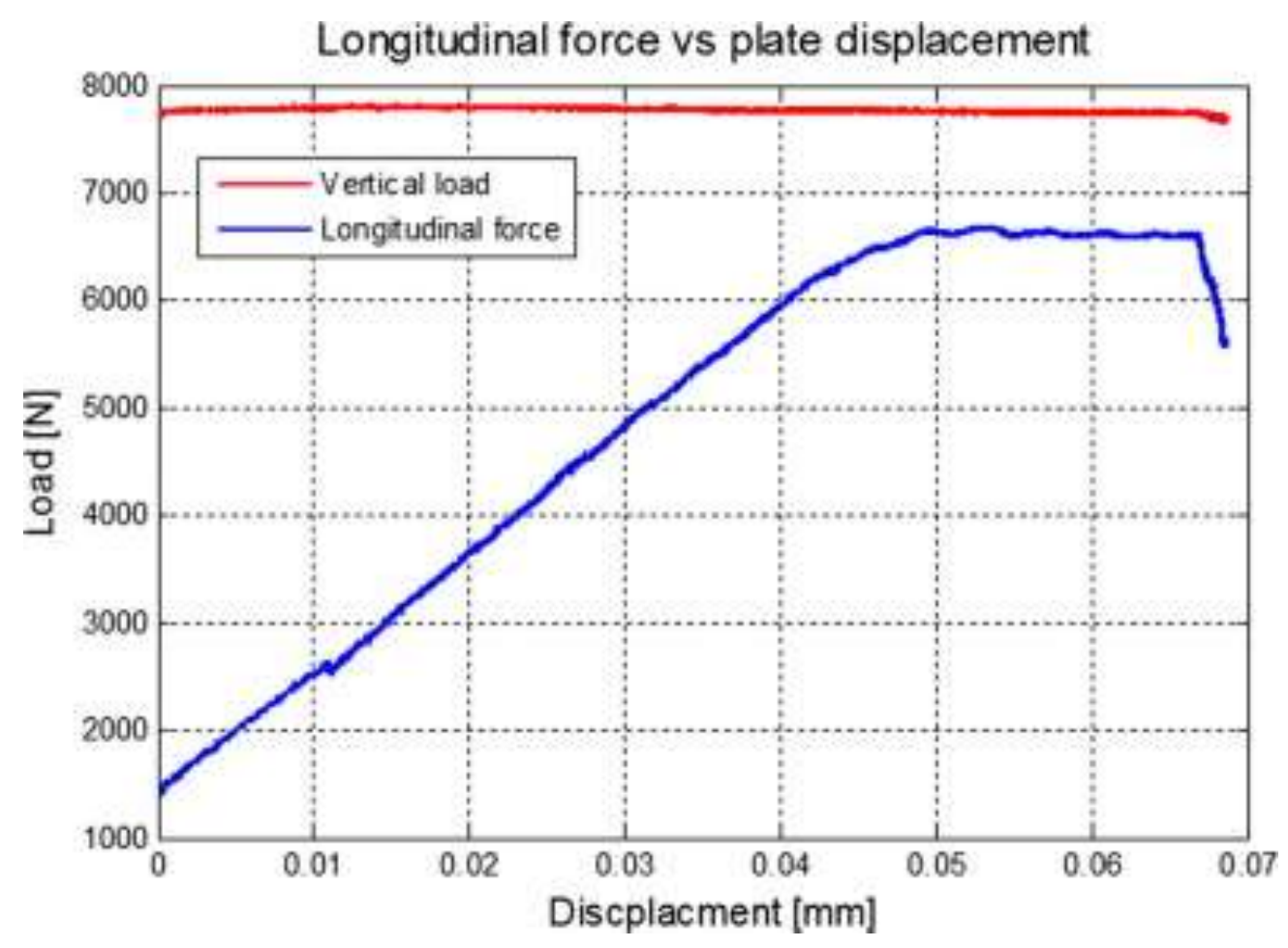

Figure 6: Longitudinal force as a function of plate longitudinal displacement

\subsubsection{Modal analysis}

A modal analysis was conducted to capture the first six vibrational modes of the tyre, as discussed by Cosin (2014) and Stallmann \& Els (2014). The tyre was mounted horizontally on the pedestal used in the static parameterisation tests. The tyre was then excited by an impulse from a hydraulic actuator, thus exciting a large range of frequencies and the corresponding mode shapes of the tyre. The experimental setup is shown in Figure 7. 


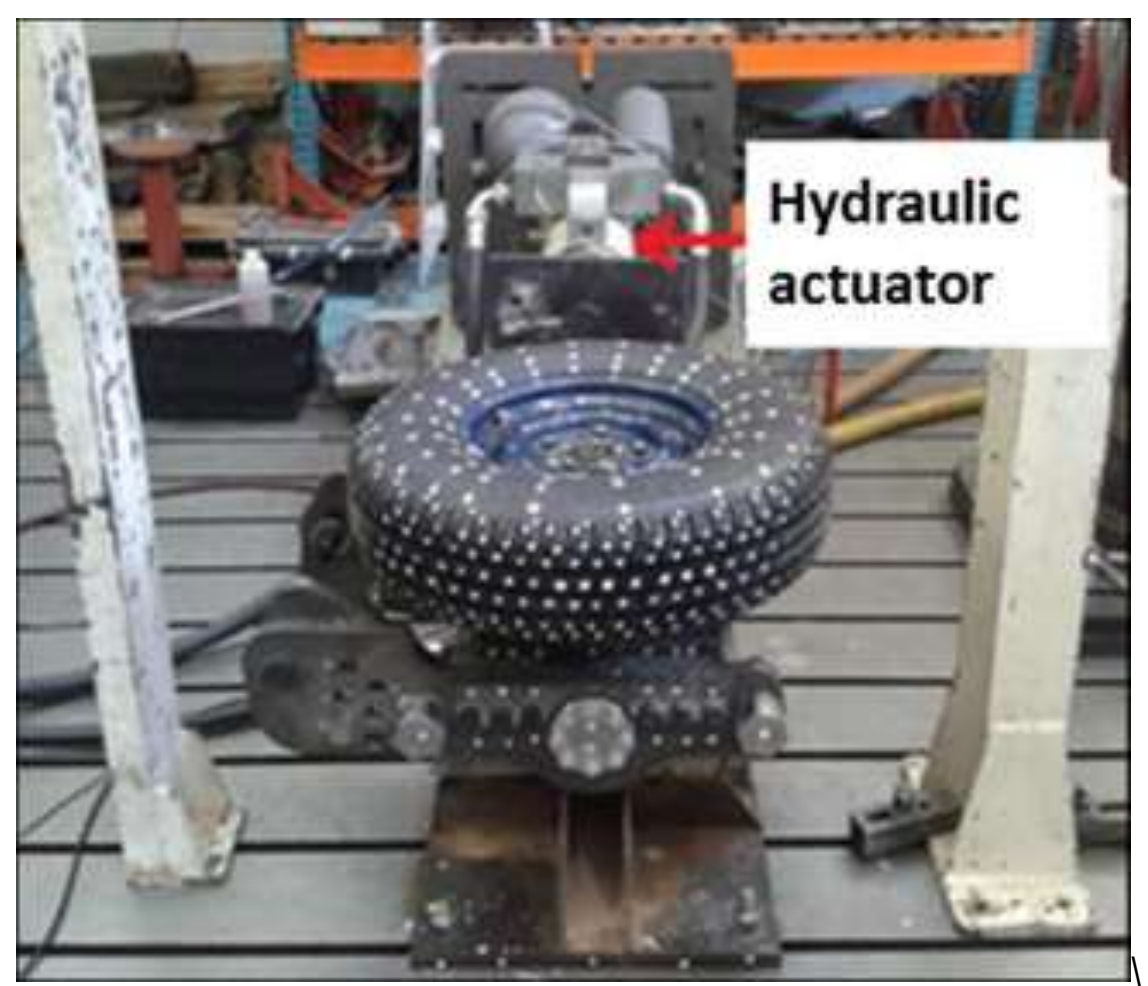

Figure 7: Experimental setup used to determine modes two to six

A Polytec PSV - 400 (Polytec, 2014) scanning laser vibrometer was placed directly above the tyre to measure the vibrational response of each piece of reflective tape on the sidewall of the tyre. This allows the Polytec PSV - 400 (Polytec, 2014) scanning laser vibrometer to capture the vibrational modes.

To capture vibrational modes 2 and 5 as defined by Cosin (2014) the the Polytec PSV - 400 (Polytec, 2014) scanning laser vibrometer is placed in front of the tyre to capture the vibrational response of each piece of reflective tape on the tread of the tyre, as depicted in Figure 7.

By making use of a PSV Software package, which generates a frequency response function (FRF) of the measured vibrational response of the tyre, the frequencies at which the respective vibrational mode shapes occur were identified. The FRF displayed an operational deflection shape of all measured points (reflective tape strips) which were analysed during the testing procedure from which the respective frequencies and corresponding mode shapes were identified.

The torsional natural frequency (first mode) of the tyre was determined from the moment about the wheel's spin axis. The angular tyre displacement was measured by the WFT's (Becker \& Els, 2012) 11 
single turn potentiometers, which are able to accurately measure 0.5 degrees of rotational displacement.

A FRF was constructed based on the angular displacement measurements captured by the WFT (Becker\& Els, 2012) single turn potentiometers and the frequency at which the in-plane rigid-body rotation mode occurred was estimated based on the resulting FRF. The modal analysis results are depicted in Table 1.

Table 1: Modal analysis results

\begin{tabular}{|c|c|c|c|c|}
\hline & \multicolumn{2}{|l|}{ 1 bar inflation pressure } & \multicolumn{2}{l|}{ 2 bar inflation pressure } \\
\hline Mode shape & Frequency (Hz) & Damping (\%) & Frequency (Hz) & Damping (\%) \\
\hline $\mathbf{1}$ & 26.1 & - & 28.4 & - \\
\hline $\mathbf{2}$ & 24.2 & 4.21 & 26.1 & 3.87 \\
\hline $\mathbf{3}$ & 32.5 & 3.17 & 37.9 & 3.53 \\
\hline $\mathbf{4}$ & 46.9 & 2.48 & 49.9 & 2.10 \\
\hline $\mathbf{5}$ & 52.6 & 0.92 & 55.9 & 0.04 \\
\hline $\mathbf{6}$ & 64.4 & 0.43 & 68.2 & 0.12 \\
\hline
\end{tabular}

\subsection{Dynamic parameterisation}

Dynamic field tests were conducted to obtain dynamic parameterisation and validation data. The dynamic field tests were conducted using an outdoor tyre test trailer, shown in Figure 8, at Gerotek Test Facilities (2013).

The outdoor tyre test trailer consists of a mainframe and a sub-frame, which are linked with six single-component load cells (three vertical, two lateral and one longitudinal load cell). The right-hand side wheel hub is mounted to the sub-frame and all the forces generated by the right-hand side tyre are measured by the six load cells. The same WFTs described in Section 2.1 (Becker \& Els, 2012) were 
implemented to verify the forces and moments generated by the tyres. The WFT (Becker \& Els, 2012) data is used in the validation process of the FTire model.

The outdoor tyre test trailer is fitted with adjustable hubs which allow for various camber, slip and caster angle adjustments. Furthermore, a detachable pneumatic-hydraulic braking system, used during dynamic braking testing procedures, is fitted to the outdoor tyre test trailer.

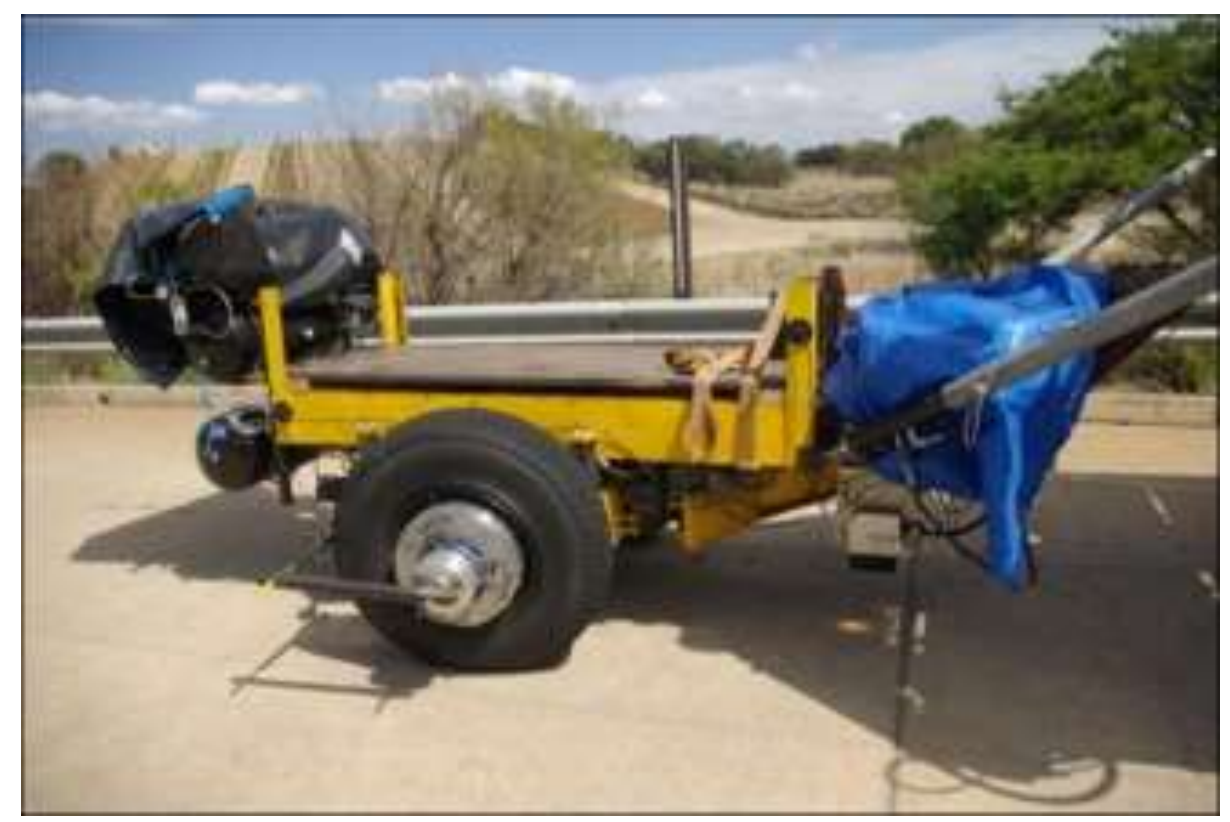

Figure 8: The tyre testing rig

Dynamic parameterisation and validation tests are conducted at several vertical loads. The vertical load is increased and decreased by adding or removing $200 \mathrm{~kg}$ steel plates to the tyre test trailer's load bed. The speeds at which the tests are conducted are governed by the vehicle towing the tyre test trailer and are kept as constant as possible during testing procedures.

Vertical parameterisation tests were conducted over discrete obstacles, specifically several different cleats. The measured vertical force when negotiating the cleats give consistent results, as depicted in Figure 9. The tyre's response when the trailer is towed over the cleats gives an indication of the tyre's vertical damping characteristics. 


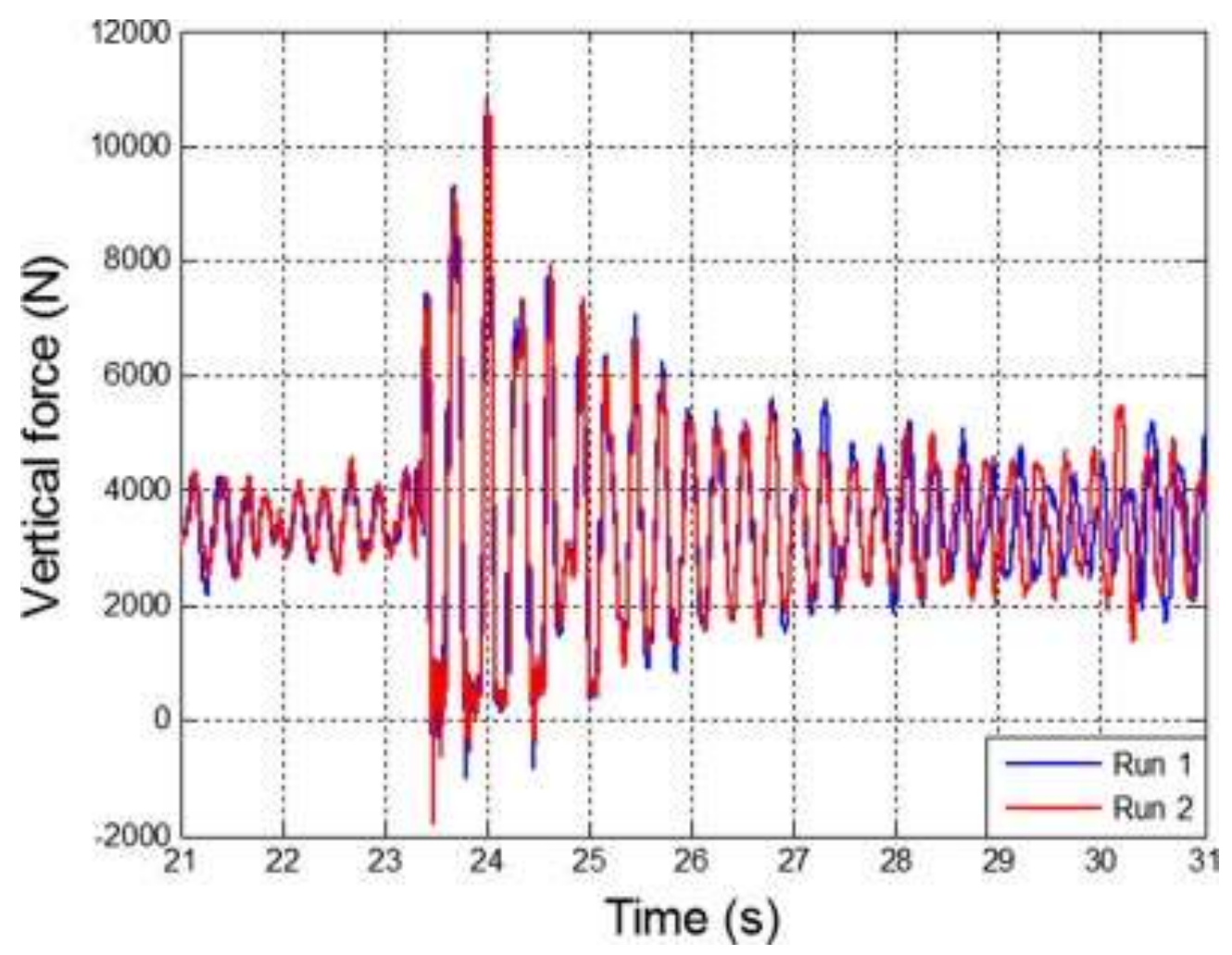

Figure 9: 50mmx50mm dynamic cleat test

\subsection{FTire model parameterisation}

The parameterisation test data, obtained from tests described in Section 2, were used to parameterise the FTire model using the procedure described by Cosin FTire/fit. FTire/fit (2014) is laid out in such a way that it guides the user through a step by step process to correctly parameterise the tyre model.

The parameterisation test results were provided as inputs to FTire/fit in form of TYDEX and bitmap files. FTire/fit determines the type of test executed, as well as additional information about the applicable test (such as camber angle, tyre inflation pressure as well as cleat shape and orientation) and then attempts to replicate the test with the FTire model characteristics.

FTire/fit has an identification procedure that attempts to optimise the tyre model parameters to improve the correlation between the measured and modelled results.

Figures 10 to 13 give FTire/fit parameterisation results which depict the correlation between the parameterised FTire prediction results and measured parameterisation test data. Figure 10 depicts the footprint predicted by FTire (the red outline) as well as the measured footprint. The horizontal red line 
is $100 \mathrm{~mm}$ in length and gives an indication of the scale used in the figure (the scale is the same in the vertical and horizontal direction). Figure 11 compares the vertical stiffness on a flat plate as predicted by FTire with that measured during quasi-static parameterisation. The vertical stiffness over a cleat is shown in Figure 12 as estimated by FTire and measured during the tests. Finally, Figure 13 shows the lateral tyre stiffness results as estimated by FTire and measured during laboratory tests.

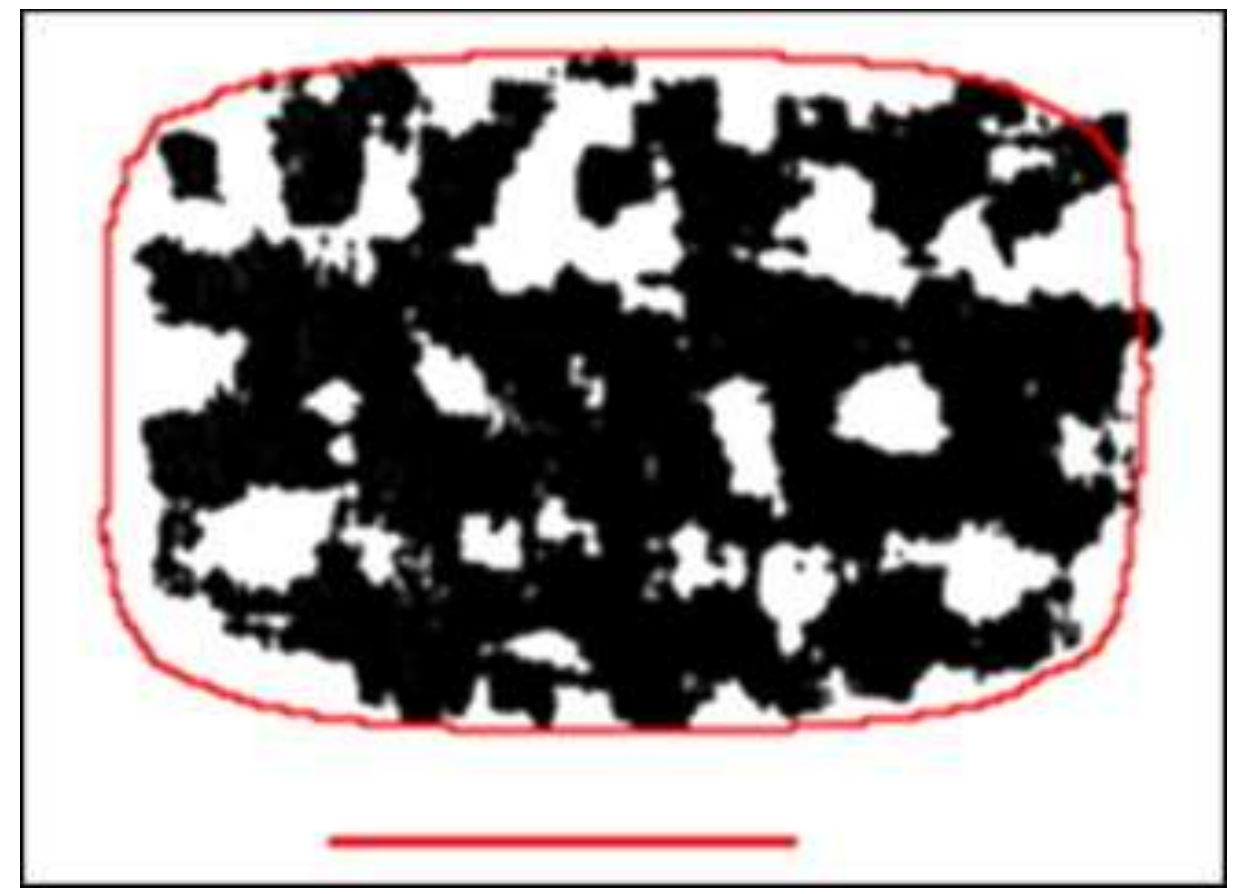

Figure 10: Tyre footprint as predicted by FTire and measured at $0^{\circ}$ camber angle and $200 \mathrm{kPa}$ inflation pressure and a vertical load of $5.6 \mathrm{kN}$ 


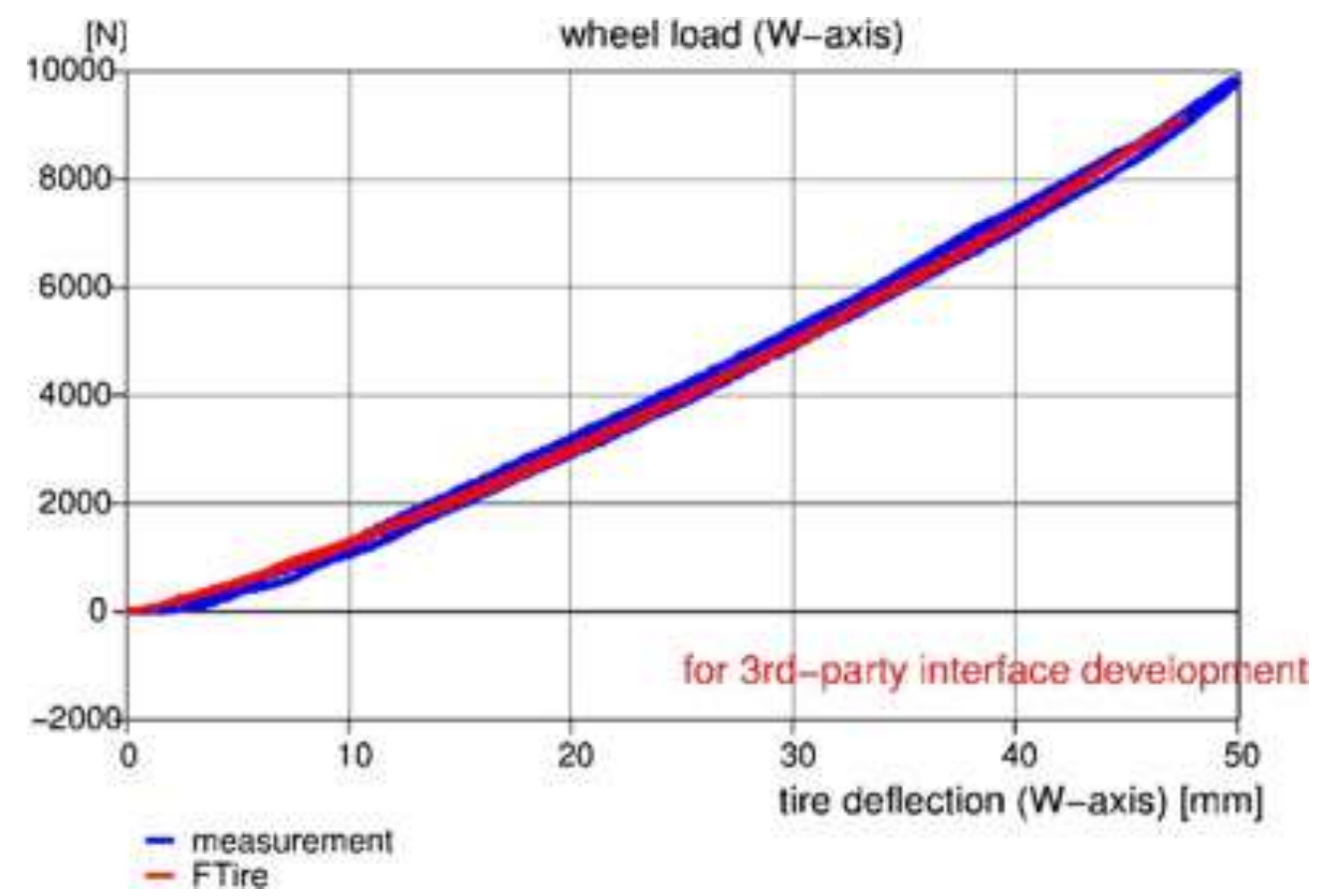

Figure 11: Vertical stiffness on a flat plate at $0^{\circ}$ camber and $200 \mathrm{kPa}$ inflation pressure

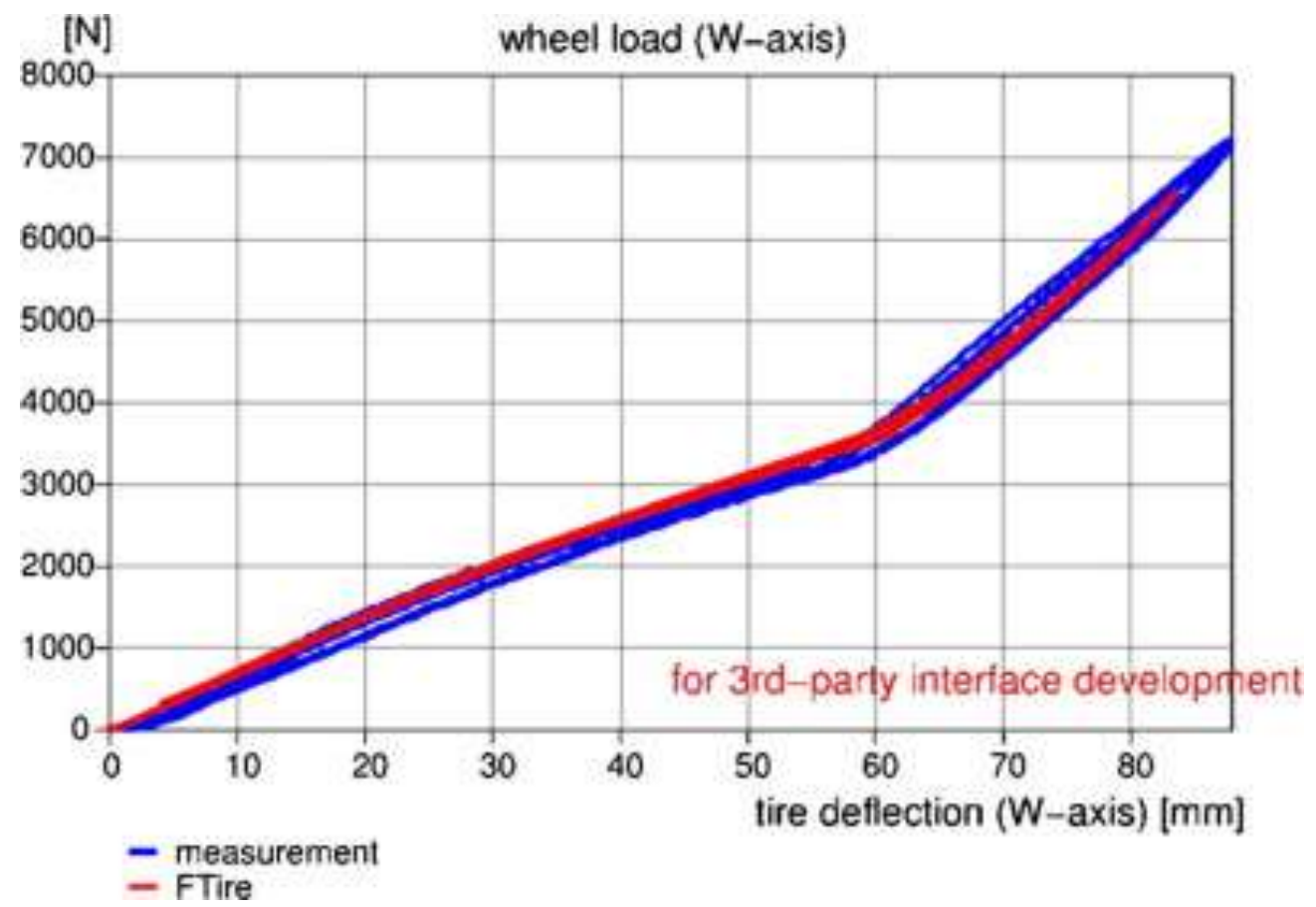

Figure 12: Vertical stiffness on a $25 \times 25 \mathrm{~mm}$ cleat at $3^{\circ}$ camber angle and 1 bar inflation pressure 


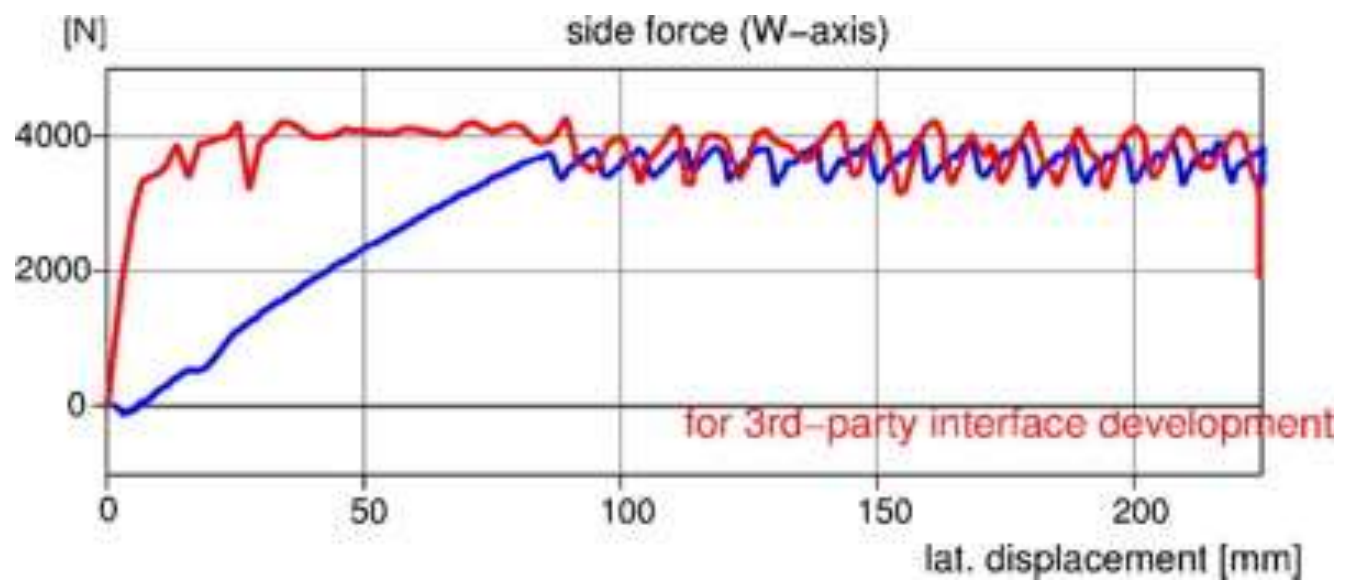

Figure 13: Lateral tyre stiffness at 100kPa inflation pressure, 0 degrees camber and $3.61 \mathrm{kN}$ vertical load (blue is measured and red simulated)

It is clear that the FTire model captures the static tyre footprint and vertical tyre force vs. displacement characteristics very accurately. Furthermore, it was seen that the in-plane and out-ofplane tyre force vs. displacement characteristics are captured acceptably accurately by the FTire model.

Stallmann et al. (2014) suggested that the tyre damping parameters be parameterised manually by making use of the dynamic cleat test parameterisation data which is obtained from dynamic tests, as discussed in Section 2.2. The damping parameters are adjusted incrementally until the measured dynamic cleat test data results correlate with the FTire model prediction behaviour, as shown in Figure 14. This method of adjusting the tyre damping parameters proved to be a cumbersome and time consuming but effective process. 


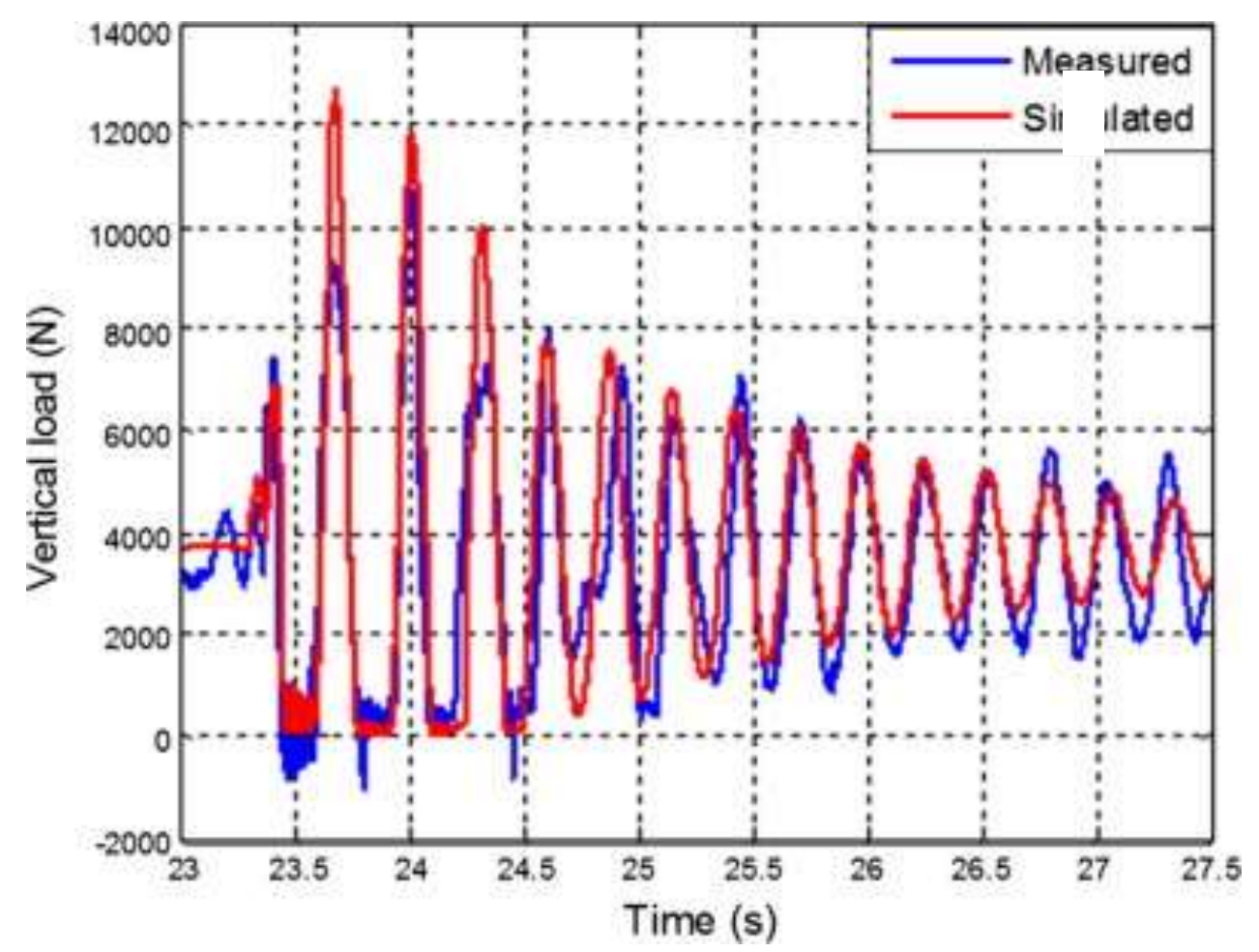

Figure 14: 50x50mm cleat test damping correlation

From Figure 14 it is seen that the dynamic vertical tyre characteristics are captured accurately by the FTire model.

\section{Tyre model validation}

Validation forms an integral part of the modelling process. The validation process is aimed at comparing simulation data results to experimental data results. The comparison of these data sets can readily show correlations or discrepancies between data sets.

\subsection{Validation tests}

\subsubsection{Lateral}

The lateral validation tests were conducted on a smooth road surface and consist of sweeping the slip angle between -1 and 9 degrees as well as varying the camber angle between -2 and 2 degrees in discrete increments of two degrees. The measured lateral validation tests proved to be repeatable and gave consistent results, as seen in Figure 15, which depicts lateral force measurement results as the tyre's slip angle is increased from -1 to 9 degrees. 


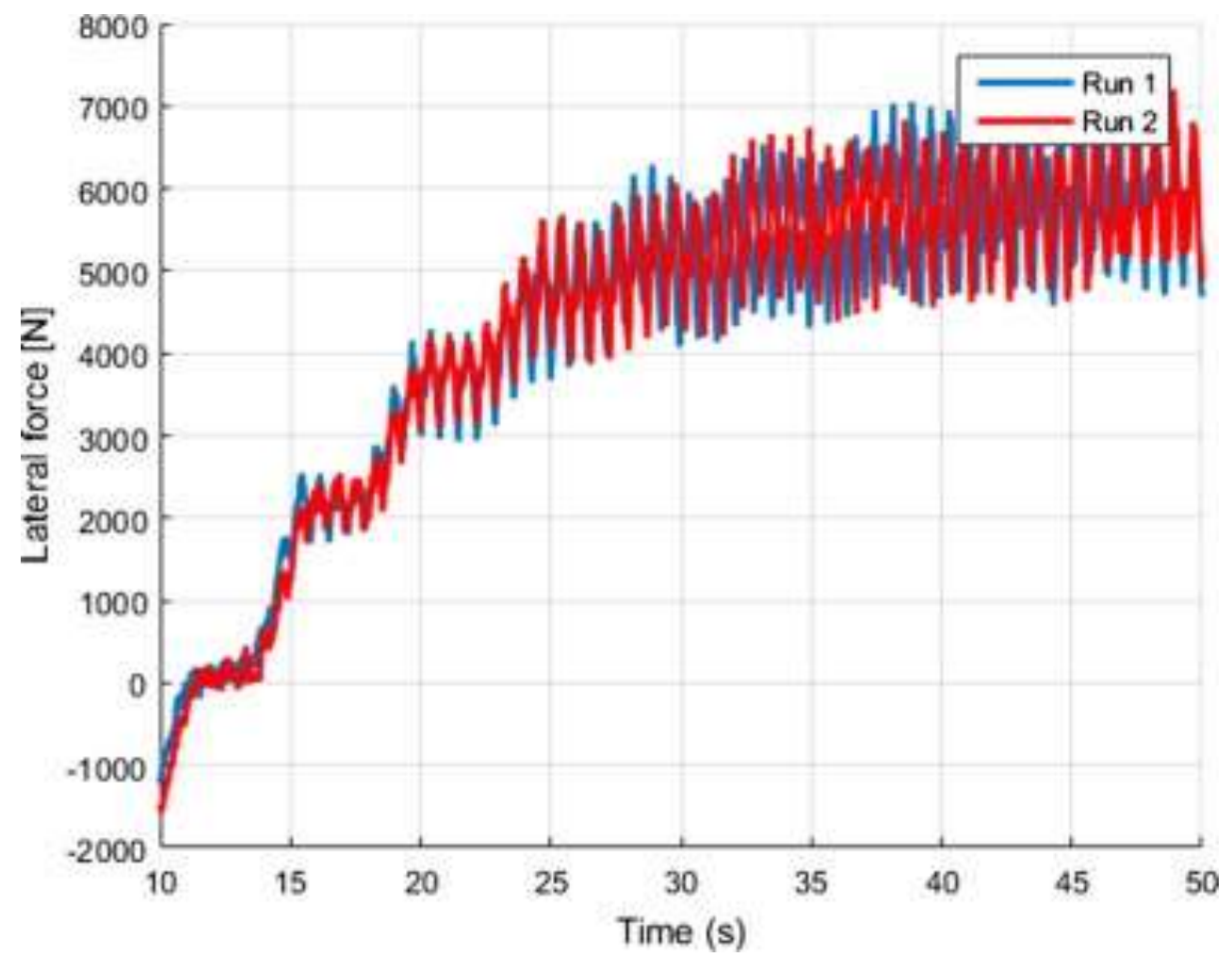

Figure 15: Lateral validation test result at a vertical load of $6.9 \mathrm{kN}$ and at $0^{\circ}$ camber angle with an inflation pressure of $200 \mathrm{kPa}$.

\subsubsection{Longitudinal}

The longitudinal force validation tests were conducted on a smooth road surface and consist of applying a brake torque to the wheels while measuring brake force and wheel speed. The traction validation tests proved to be repeatable and gave consistent results, as seen in Figure 16, which depicts longitudinal force measurement results. 


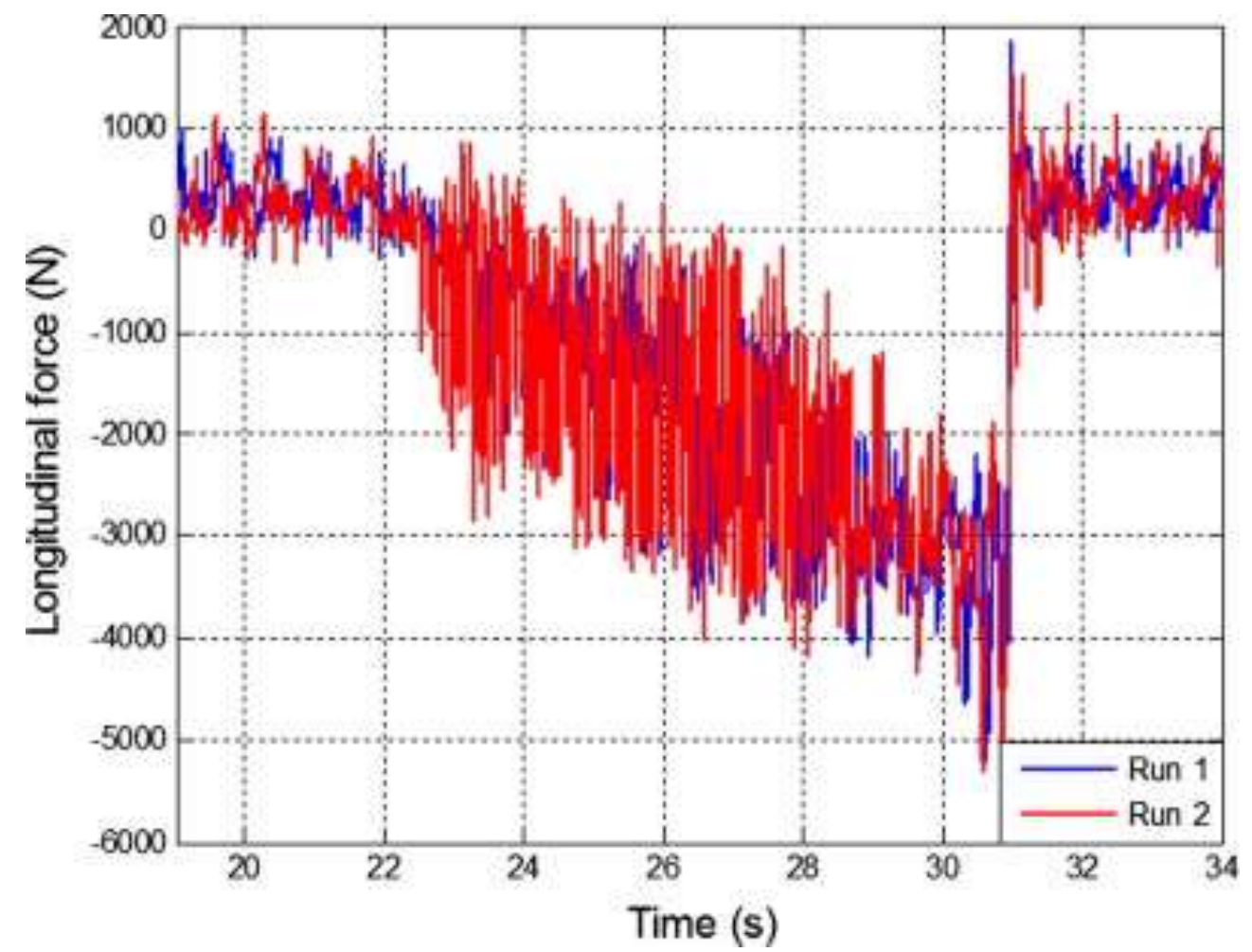

Figure 16: Longitudinal validation test results at $5.1 \mathrm{kN}$ vertical load and $200 \mathrm{kPa}$ inflation pressure per tyre

From Figure 16 it was observed that the measured data showed a very noisy signal for both runs, which may be attributed to the outdoor tyre testing trailer's bouncing motion during validation testing procedures. This bouncing motion caused a significant amount of noise in the validation measurement data results. The bouncing may be attributed to the very low damping present in the system, because the test trailer has no suspension. The only damping present in the system is that of the tyres, which is very low.

\subsubsection{Vertical}

To validate the vertical behaviour of the tyre model, the tyre test trailer is towed over discrete obstacles (as discussed in Section 2.2) and undulating road surfaces at the Gerotek Test Facilities (2013). The undulating road surface on which testing is conducted is the Belgian Paving, which gives an almost random input to the tyre. The Belgian Paving as measured with a terrain profilometer is shown in Figure 17 (Becker \& Els, 2014). The vertical validation field tests over the Belgian Paving track proved to be repeatable and give consistent results. 


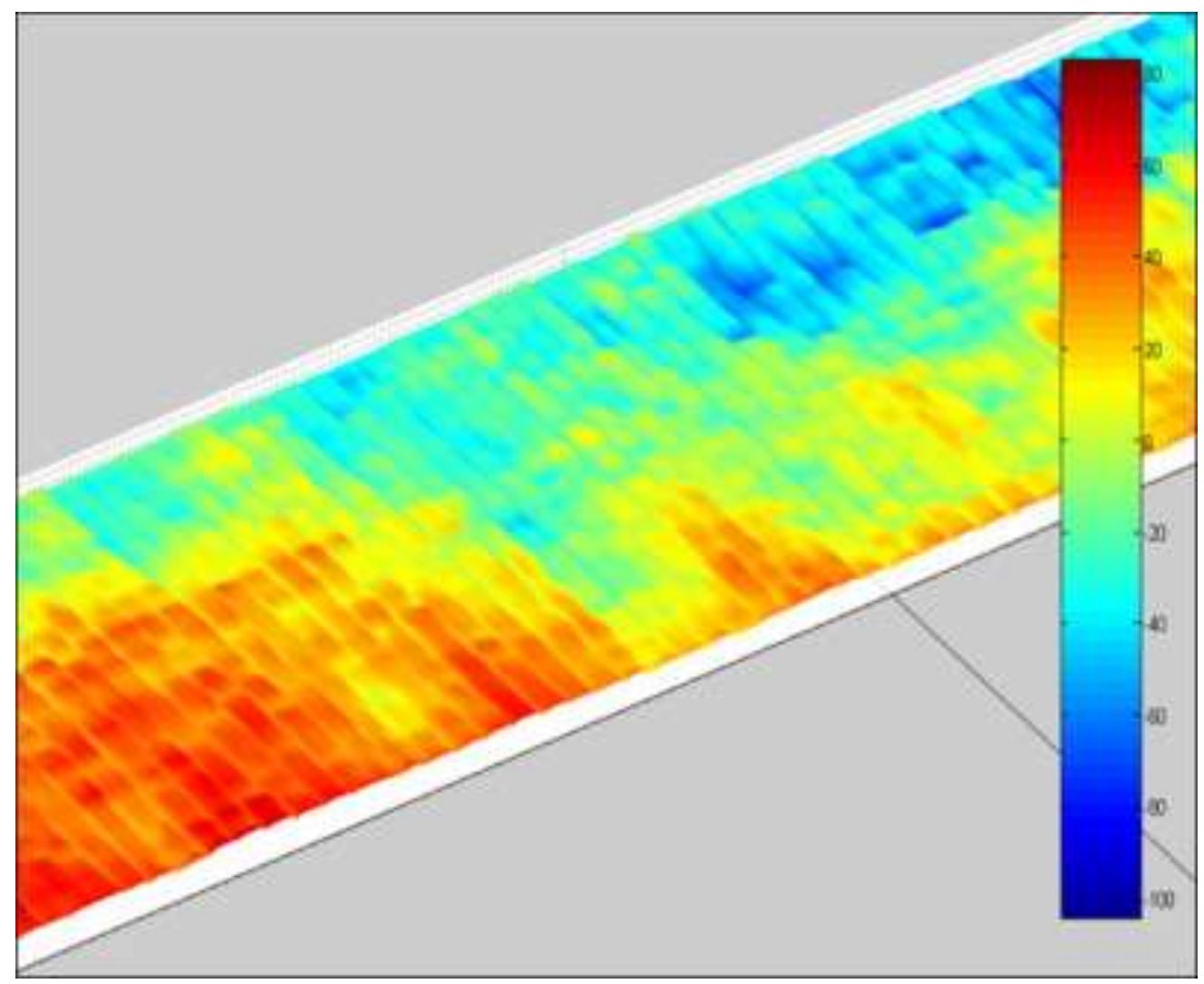

Figure 17: Belgian paving profile with scale in millimetre (Becker and Els, 2014)

\subsection{Adams model}

A high fidelity multi-body dynamics model of the outdoor tyre test trailer was developed and is implemented in MSC Adams (MSC Software Corporation, 2013) and is used to validate the FTire model. The simulation is run as a co-simulation with Matlab's Simulink (MathWorks, 2014) and is aimed to replicate the validation testing procedures as closely as possible.

The position of the centre of gravity of the outdoor tyre testing equipment was determined experimentally. Based on a pendulum method, described by Uys et al. (2006), the pitch and roll moments of inertia were determined experimentally. The centre of gravity and moment of inertia properties were utilised in the Adams validation simulations.

\subsection{Lateral tyre properties validation}

Figure 18 shows the measured and simulated results for a handling validation test conducted at $0^{\circ}$ camber angle. The measured results are seen to be very noisy containing some form of oscillatory 
disturbance signal. This disturbance signal is attributed to the bouncing motion of the tyre test trailer observed during dynamic testing procedures. It is observed that the lateral force trend followed by the measured and simulated data sets correlate at slip angles larger than $0^{\circ}$.

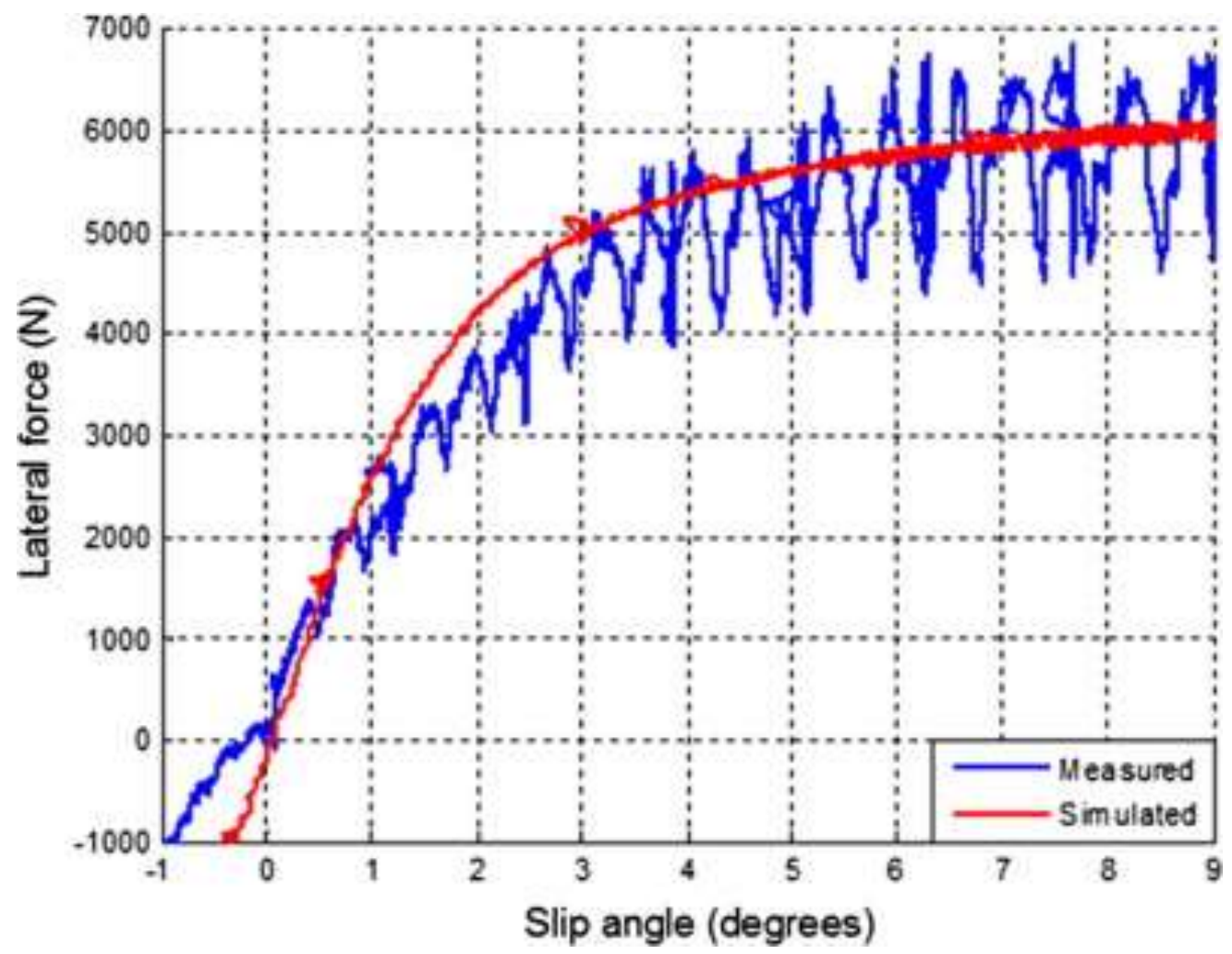

Figure 18: Lateral force vs. slip angle at 0 degrees camber angle, inflation pressure of 2 bar and a vertical load of $6,9 \mathrm{kN}$

It is seen that the FTire model is able to predict the lateral force vs. slip angle characteristics. The FTire model cornering stiffness is observed to be slightly larger than that of the actual tyre which results in the simulation results having a greater initial gradient than that of the measured data results. It is concluded that the correlation between the measured and simulated data sets is good. The FTire model is able to estimate the lateral tyre behaviour to an extent which gives acceptable results.

\subsection{Longitudinal tyre properties validation}

The longitudinal forces generated by the tyre during the dynamic validation field tests are simulated by applying a brake torque on the wheels in the simulation environment. Figure 19 shows the measured and simulated results of the traction validation test. 


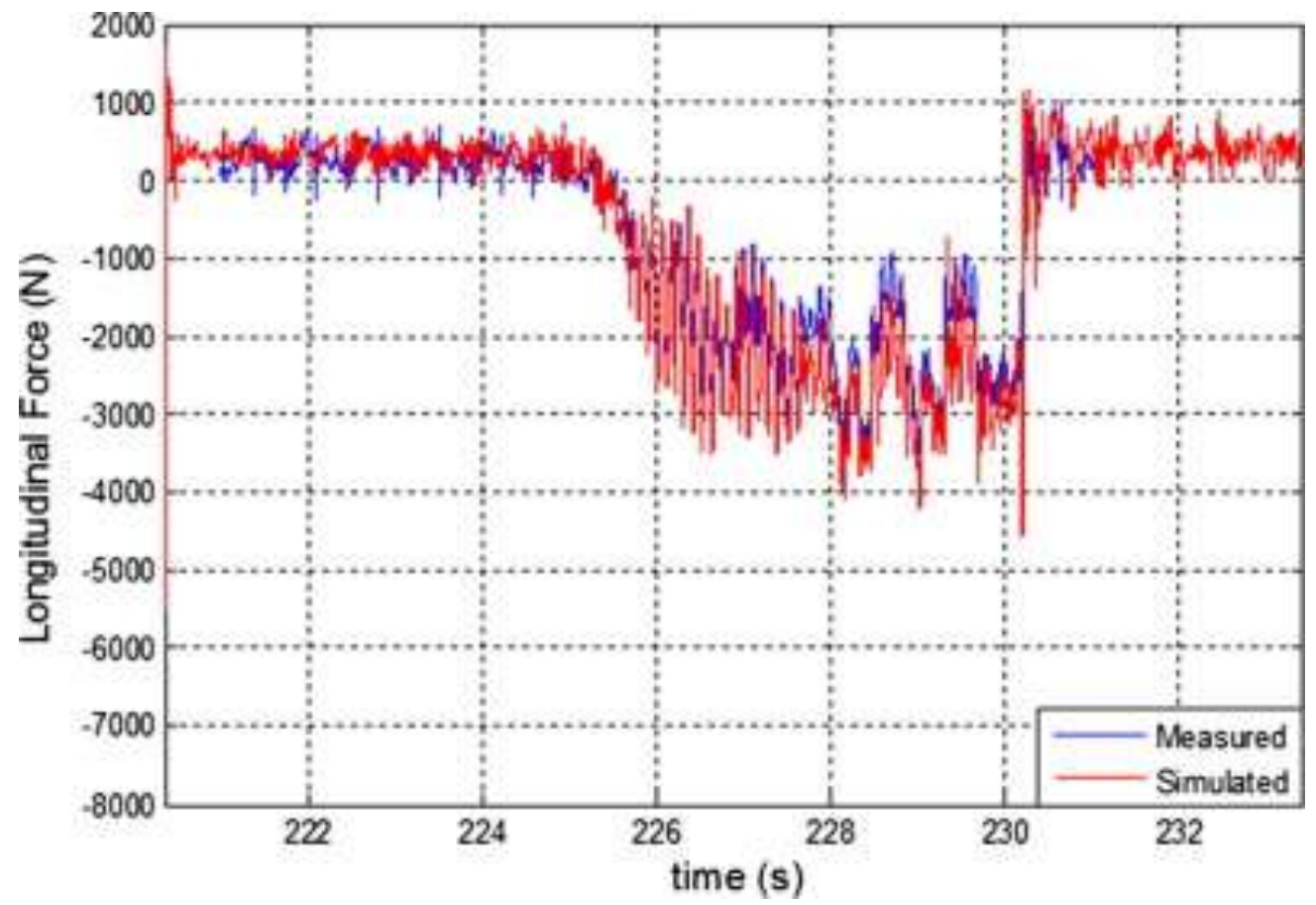

Figure 19: Longitudinal force at 2 bar inflation pressure and a vertical load of $4,4 \mathrm{kN}$

The correlation of the measured and simulated data sets is good. The simulation results are seen to closely correlate with the measured results. This is due to the nature of the simulation input, namely the measured brake torque applied to the wheels of the simulation model which is derived from the brake line pressure as measured during the validation tests as well as the brake torque measured by the Wheel Force Transducer (Becker and Els, 2012).

\subsection{Vertical tyre properties validation}

The validation of the FTire model in the vertical direction consists of two sections. The first section deals with the validation of the tyre model over discrete obstacles and the second section deals with the validation of the tyre model over rough terrain.

\subsubsection{Discrete obstacles}

The discrete obstacle tests include dynamic cleat tests, as discussed in Section 2.2.1. The discrete obstacle validation consists of two parts. The first part looks at the way the tyre encounters the obstacle and the second part consists of the tyre behaviour after the obstacle was negotiated. 
Figure 20 shows the measured and simulated results of a 50x50mm cleat test with a vertical load of $3.6 \mathrm{kN}$. It is seen that the cleat encounter is approximated well by the simulation model. The tyre behaviour prediction after the obstacle has been negotiated is seen to deviate slightly between the measured and simulated signals. However, this is largely attributed to measurement noise experienced during the field tests as well as non-linear tyre damping associated with dynamic tyre damping behaviour.

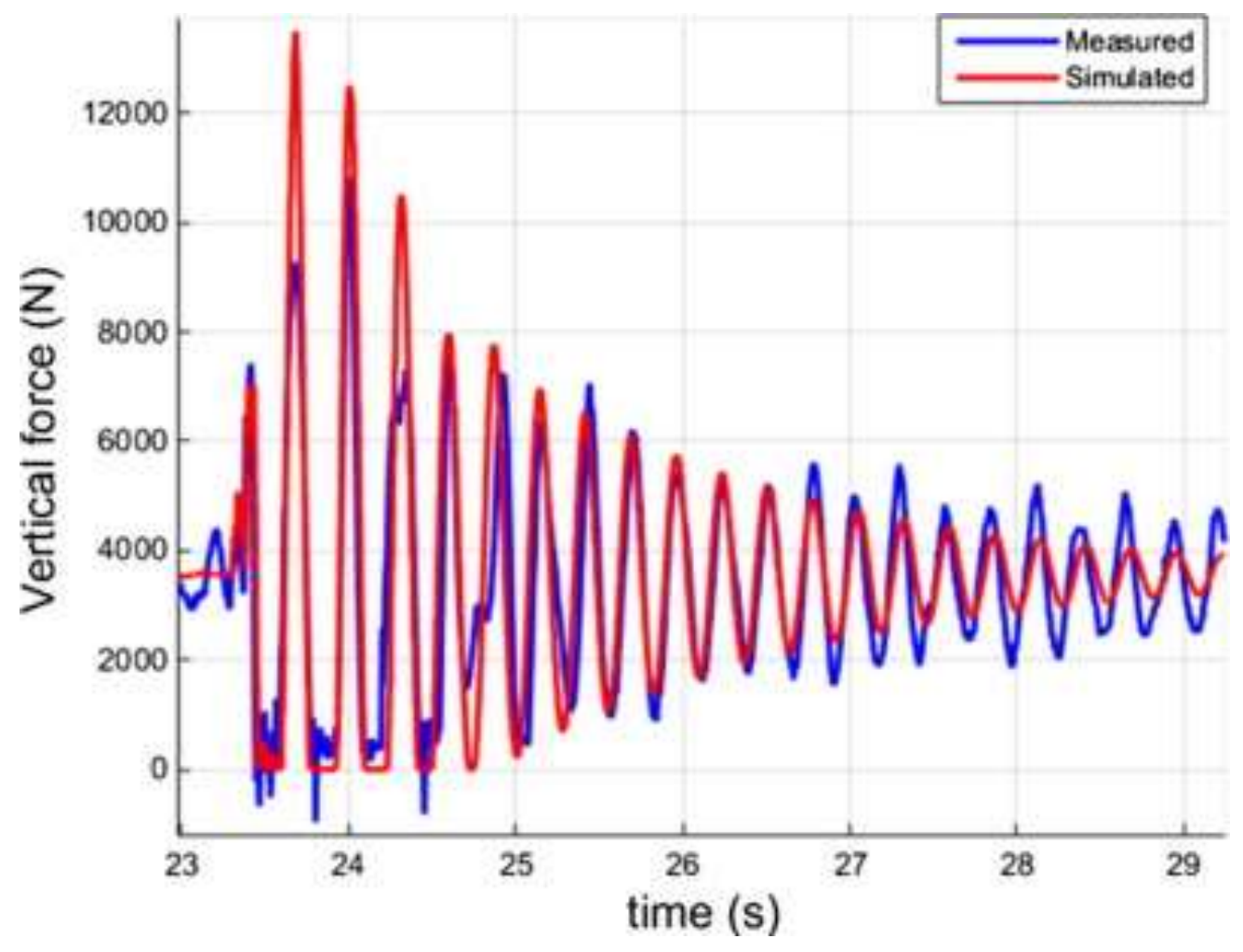

Figure 20: Measured and simulated 50x50 $\mathrm{mm}$ cleat test at an inflation pressure of $200 \mathrm{kPa}$ and a vertical load of $3.6 \mathrm{kN}$

Based on the validation results it is determined that the FTire model is able to accurately predict the tyre's response of the cleat encounter for all cleat tests that were performed.

\subsubsection{Rough terrain}

The track on which the rough terrain tests were conducted was the Belgian paving track, as discussed in Section 2.2.1, for which an accurate three dimensional profile is available for use in simulations (Becker \& Els, 2014). 
Figure 21 shows the measured and simulated signal responses over the Belgian paving. It is difficult to ensure that the tyre test trailer model negotiates exactly the same path as the tyre test trailer did in the field test. Even a slight discrepancy in speed and path may result in significant variation when comparing the simulation and experimental results in the time domain.

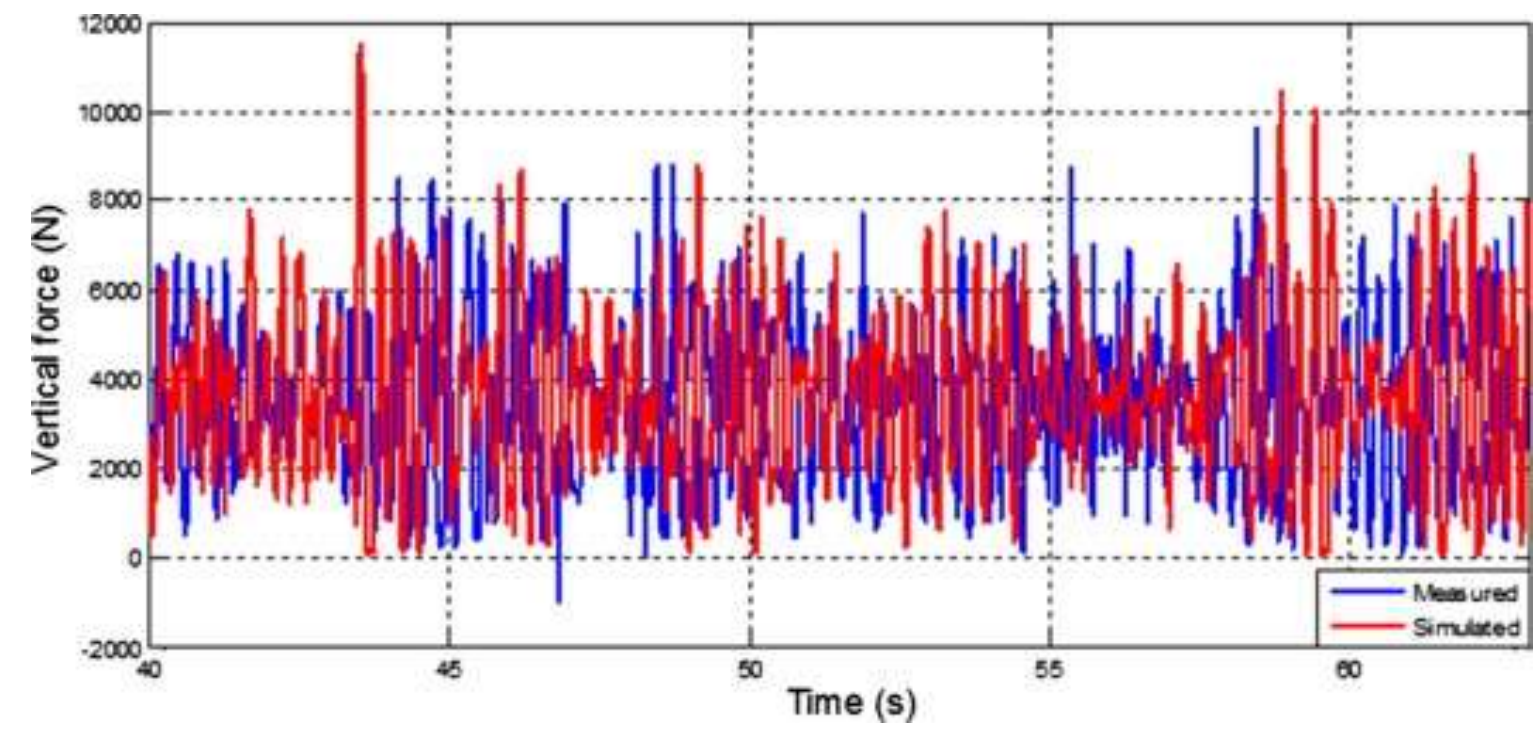

Figure 21: Measured and simulated results of the Belgian paving (LC0) at $3.5 \mathrm{~m} / \mathrm{s}$

Clearly a validation in the time domain will result in an unsatisfactorily correlation due to the deviation between the measured and simulated signals. Rather than comparing tests and simulations in the time domain, a probability theorem approach is considered which involves the analysis of random phenomena within a signal. This validation technique comprises of determining the probability that a certain vertical load is present in a validation test as well as the corresponding simulation data set.

The mathematical probability theorem is applied as a validation method by considering the Gaussian distribution of each of the validation test and simulation time signals. The Gaussian distribution is able to accurately predict the probability that any observation or signal will fall between any two real predefined limits, as illustrated in Figure 22. 


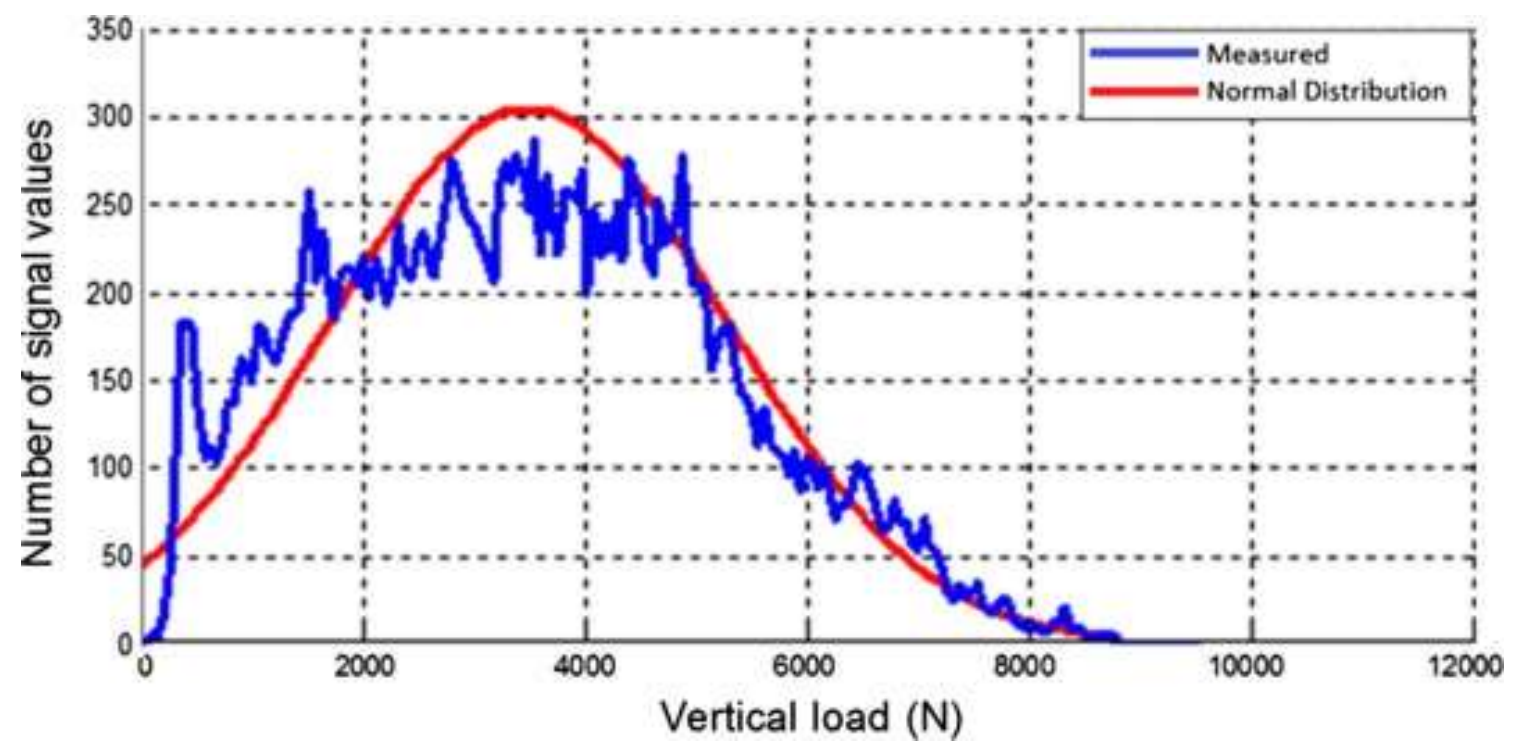

Figure 22: Gaussian distribution of the tyre's vertical force behaviour over the Belgian paving

Figure 23 depicts a histogram of the measured and simulated tyre's vertical force behaviour over the Belgian Paving.

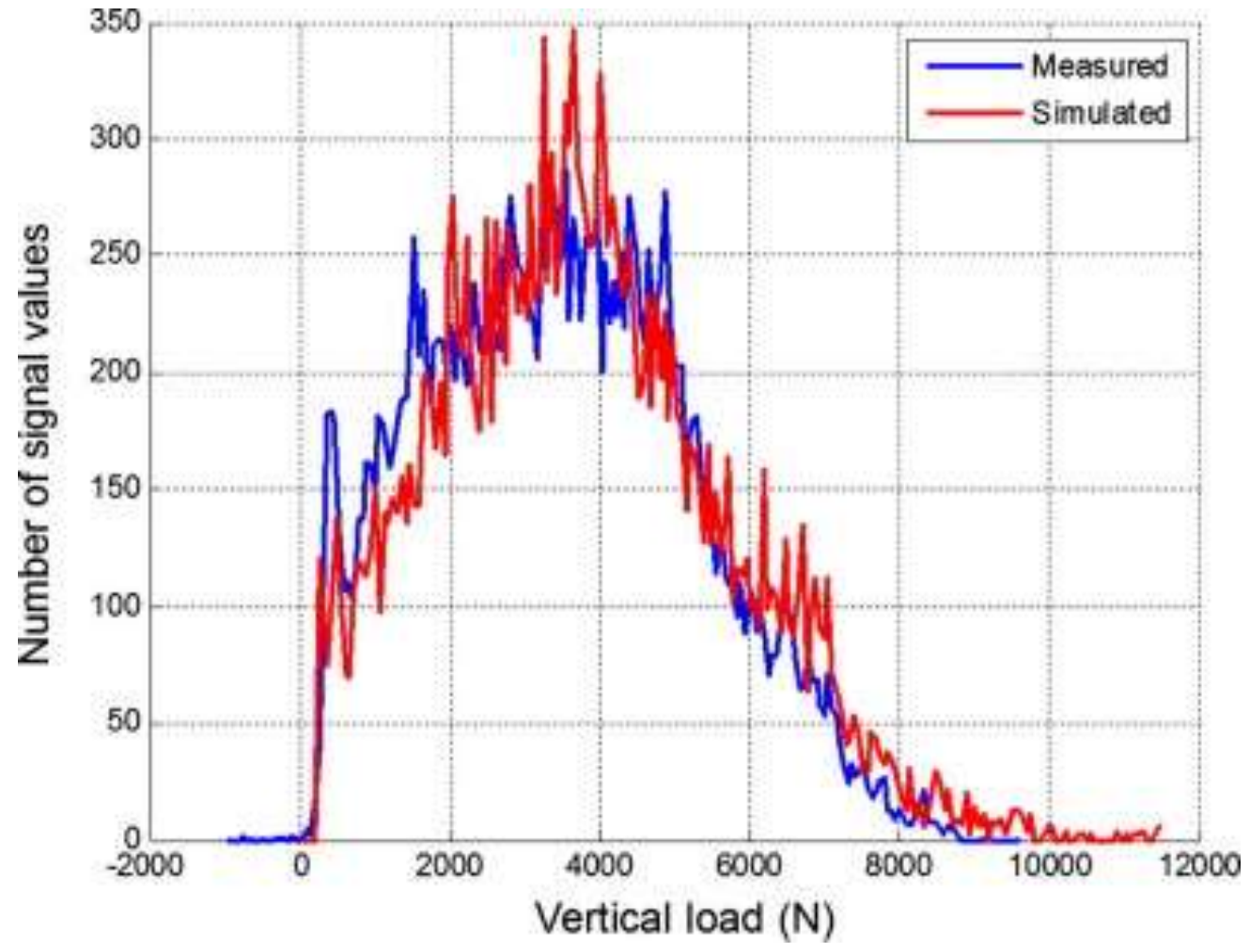

Figure 23: Histogram of the measured and simulated tyre's vertical force behaviour over the Belgian paving 


\section{Tyre model implementation}

As a final validation step, the tyre model was implemented on a fully nonlinear multi-body dynamics model of a Land Rover Defender, developed in MSC Adams (MSC Software Corporation, 2013). The Land Rover Defender is used as a vehicle dynamics research platform. A longitudinal dynamics model of the Land Rover Defender was developed by Hamersma and Els (2014). The longitudinal vehicle dynamics model accurately modelled the engine torque curves, transmission, braking and aerodynamic drag forces. Included in the model are experimentally determined mass and moments of inertia properties (Uys et al., 2006) and an accurate model of the hydropneumatic suspension implemented on the vehicle (Van der Westhuizen \& Els, 2015).

The Land Rover Defender was instrumented with the WFT developed by Becker and Els (2012), as well as a proximity switch to measure wheel speed, and a NovAtel SPAN-CPT Single Enclosure GNSS/INS Receiver (Novatel Inc.). The data was recorded on a Helios Single Board Computer (Diamond Systems) at a sampling frequency of $1000 \mathrm{~Hz}$.

To compare the developed tyre model with field measurements, brake tests were conducted on the Belgian Paving. The Land Rover Defender was braked from approximately $45 \mathrm{~km} / \mathrm{h}$ to standstill on the Belgian Paving while measuring all the forces and moments acting on the left front tyre. These tests were repeated three times. The same tests were performed with the Adams model of the Land Rover Defender by accelerating the model to the same initial speed as recorded in the tests and then applying the measured brake torque. The HASTIFF solver was used in the SI1 formulation with a modified corrector. According to the MSC Adams solver information, the HASTIFF solver is used in conjunction with the SI1 formulation because it enables the HASTIFF integrator to monitor the integration of velocity variables which therefore results in highly accurate simulations. This formulation ensures that the velocities and accelerations that are calculated satisfy all first- and second-time derivatives. This is important, because the modelled forces are used for validation. According to Newton's Second Law, the acceleration is directly proportional to the force and hence the second-time derivative's accuracy is of utmost importance. (MSC Software Corporation, 2013). 
Figure 24 compares the measured and the modelled longitudinal (top) and vertical (bottom) tyre forces for one of the test runs. It is difficult to quantitatively compare the time-domain response of the simulated and measured results, as the real vehicle and simulation model does not drive on exactly the same part of the road. The results do indicate similar amplitudes and oscillating periods.
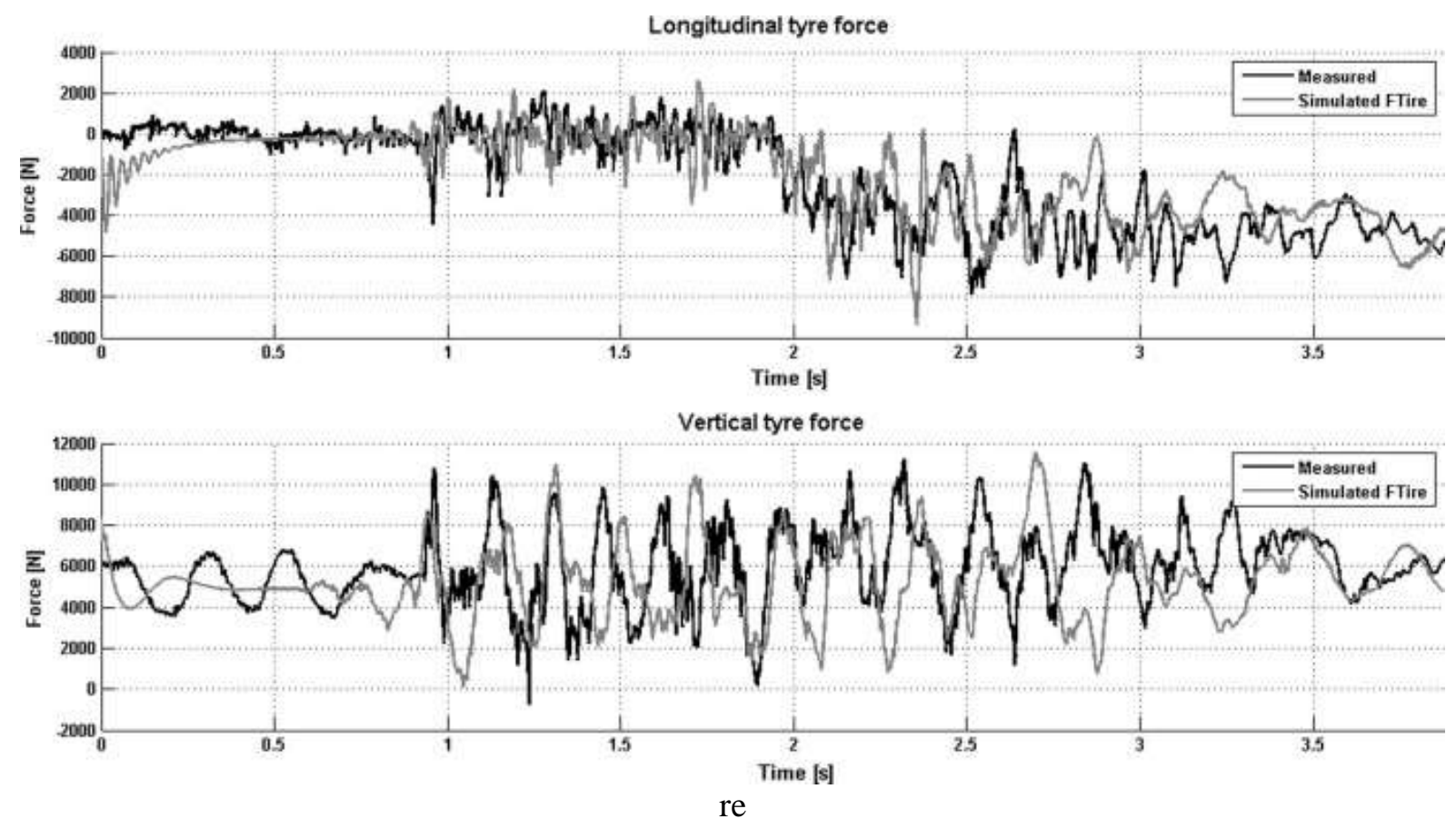

Figure 24: Time domain comparison of measured and modelled longitudinal (top) and vertical (bottom) forces.

To quantitatively compare the simulated and measured tyre forces, a Fast Fourier Transform (FFT) is performed on the measured and modelled vertical and longitudinal forces. These results are shown in Figure 25. The FFTs clearly show that there is a very good correlation between the measured and modelled tyre forces, up to at least $30 \mathrm{~Hz}$ for the vertical forces and $40 \mathrm{~Hz}$ for the longitudinal forces. The FTire model therefor accurately captures the magnitudes and frequencies of the forces for the frequency range of interest for ride and braking evaluation on rough terrain. 

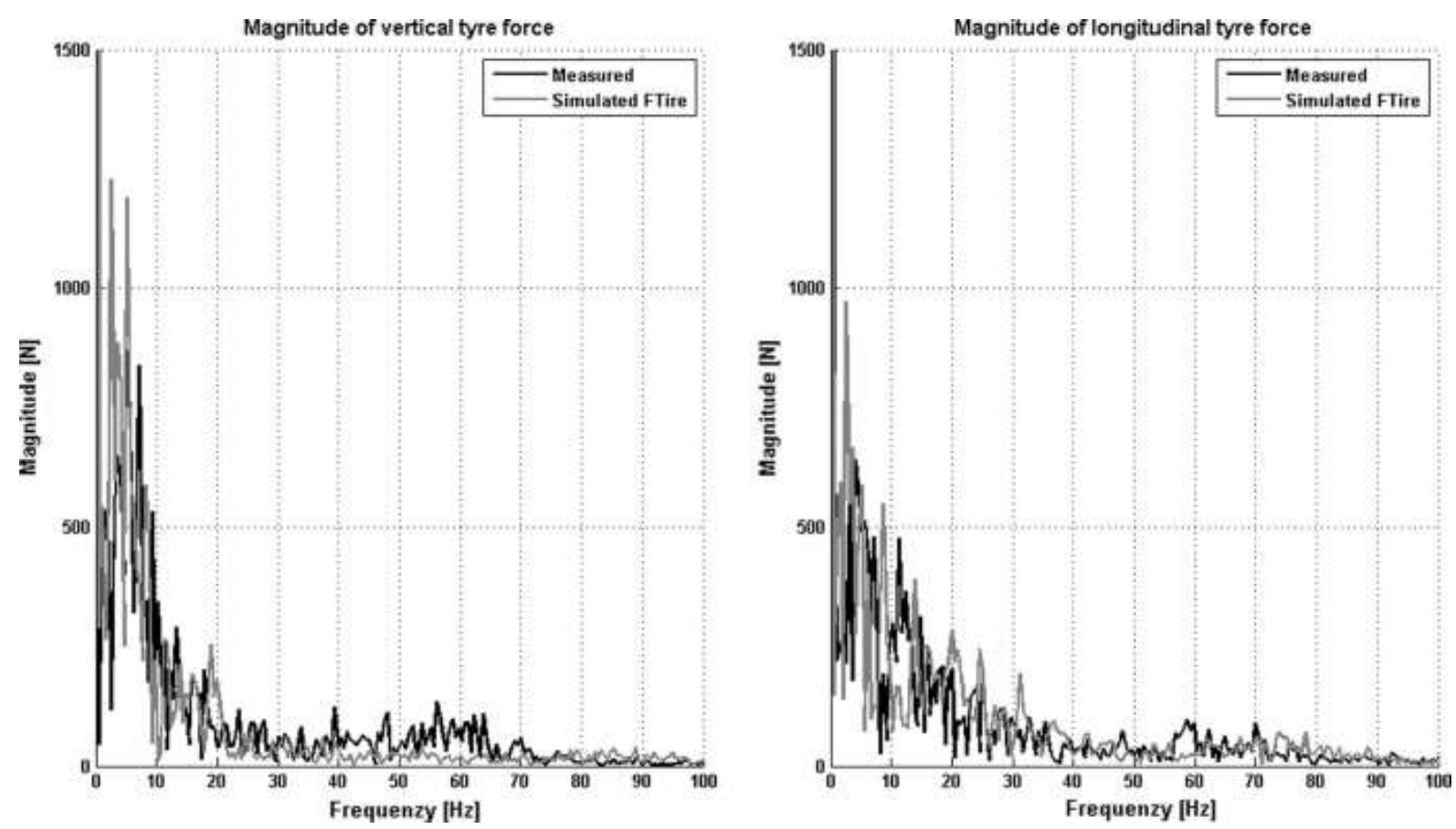

Figure 25: FFTs of vertical (left) and longitudinal tyre forces as measured and simulated

\section{Conclusion and recommendations}

The aim of this paper was to parameterise, validate and implement a physics-based model of a typical SUV tyre. To this end, an FTire tyre model was chosen as the modelling approach.

The FTire parameterisation process relies heavily on experimental data. The quasi-static parameterisation tests were performed in a laboratory environment on a non-rolling tyre. The parameterisation of the damping behaviour of the FTire model was based on dynamic cleat test results. It was necessary to perform a large number of parameterisation iterations, using mostly quasistatic test data, to obtain an FTire model with sufficient accuracy to predict tyre behaviour. Handling, traction and ride comfort validation test data was measured using a tyre test trailer.

Validation of the developed tyre model was done dynamically. An Adams model of the tyre test trailer used for validation purposes was developed and the field validation tests were repeated in the simulation environment. Based on the validation results it was found that the FTire model was able to predict the tyre behaviour with very good accuracy. Although the parameterisation was largely based on quasi-static test data, simulations of the FTire model on smooth road surfaces gave acceptable results for the handling simulations and good results for the brake simulations. The ride comfort 
simulations indicated that the FTire model was able to predict tyre behaviour over discrete obstacles accurately and acceptably over rough terrain.

The FTire model was implemented on a fully nonlinear multi-body dynamics model of a SUV in Adams. Field brake tests were performed with the vehicle on a Belgian Paving and these tests were repeated with the Adams model of the vehicle containing the developed tyre model. The difficulty of quantitatively comparing time domain data was evident and to further the comparison FFTs were done on the vertical and longitudinal tyre forces. The FFTs revealed that on the Belgian Paving, the FTire model gives good results for both vertical and longitudinal tyre forces.

The conclusion of the study may thus be summarized as follows:

The parameterised FTire model, based primarily on quasi-static parameterisation data, was able to predict the Michelin LTX A/T $235 / 85 \mathrm{R} 16$ tyre's behaviour over smooth road surfaces and hard, rough terrain. Vehicle simulations may readily incorporate the FTire model for simulations over smooth and rough terrain.

The procedure of the laboratory tests which were conducted to obtain parameterisation data for the FTire model could possibly be improved. It is recommended that, when investigating the longitudinal, lateral and torsional tyre stiffnesses the tests should be conducted on various surfaces that resemble the expected tyre operating conditions, rather than on a steel plate. This could improve the in-plane parameterisation process and aid in parameterising an improved FTire model. The bouncing present in the tyre test trailer measurements should also be eliminated if possible.

\section{References}

Bakker, E., Pacejka, H., \& Lidner, L. (1989). A new tire model with an application in vehicle dynamics studies. Autotechnologies Conference and Exposition. Monte Carlo, Monaco.

Becker, C.M. \& Els, P.S. (2014). Profiling of rough terrain. International Journal of Vehicle Design, Vol. 64, Nos. 2/3/4. 
Becker, C., \& Els, P. (2012). Wheel Force Transducer Measurements on a Vehicle in Transit.

Proceedings of the 12th European Regional Conference of the ISTVS. Pretoria, South Africa.

Cosin scientific software: FTire Product Brief. 2014. cosin scientific software: FTire Product Brief. Retrieved 10 January 2014, from http://www.cosin.eu/prod_FTire..

Diamond Systems. (n.d.). http://www.diamondsystems.com/products/helios. Retrieved March 5, 2015, from Helios SBC: http://www.diamondsystems.com/products/helios

Gerotek Test Facilities. (2013). Retrieved 20 July 2014, from

http://www.armscordi.com/SubSites/Gerotek1/Gerotek01_landing.asp

Gillespie, T. (1992). Fundamentals of Vehicle Dynamics. Warrendale, PA: Society of Automotive Engineers, Inc.

Gipser, M. (2002). ADAMS/FTire - A Tyre Model for Ride \& Durability Simulations, Adams User Conference. Tokyo. 2000. Retrieved 2 February 2014, from http://www.cosin.eu/literature

Gipser, M. (2005). FTire: a physically based application-oriented tyre model for use with detailed MBS and finite-element suspension models. Vehicle System Dynamics: International Journal of Vehicle Mechanics and Mobility, Vol. 43 (Supplement 1), pp. 76-91.

Gipser, M., Hofmann, G., (2013) “FTire - Flexible Ring Tire Model,” München, Germany. Hamersma, H.A., Els, P.S. (2014). Longitudinal vehicle dynamics control for improved vehicle safety. Journal of Terramechancis, Volume 54. pp. 19-36.

MathWorks, (2014). MATLAB The Language of Technical Computing. Retrieved 19 August 2014, from http://www.mathworks.com/products/matlab/

MSC Software Corporation. (2013). The Multibody Dynamics Simulation Solution. Retrieved July 18, 2013, from http://www.mscsoftware.com/product/adams

NovAtel Inc. (n.d.). SPAN-CPT Single Enclosure GNSS/INS Receiver. Retrieved December 2, 2015, from http://www.novatel.com/products/span-gnss-inertial-systems/span-combined-systems/span-cpt/ 31 
Stallmann, M. J., Els, P. S., Becker, C.M., 2014. Parameterisation and modelling of large off-road tyres for ride analyses: Part 1 - Obtaining parameterisation data. Journal of Terramechanics, Volume $55,73-84$.

Uys, P., Els, P., Thoresson, M., Voigt, K., \& Combrinck, W. (2006). Experimental determination of moments of inertia for an off-road vehicle in a regular engineering laboratory. International Journal of Mechanical Engineering Education , 34 (4), 291-314.

Van der Westhuizen, S.F., Els, P.S. (2015) Comparison of different gas models to calculate the spring force of a hydropneumatic suspension. Journal of Terramechanics, Volume 57. pp. 41-59 